\title{
INTEGRATION AND PERSISTENCE OF \\ ESCHERICHIA COLI O157:H7 86-24 \\ IN A NATURALLY-OCCURRING \\ WATER WELL BIOFILM
}

By

Debbie Kolozsvari, B.Sc. (Waterloo, 1996)

A thesis presented to Ryerson University in partial fulfillment of the requirements for the degree of Master of Applied and Environmental Science and Management

Toronto, Ontario, Canada, 2005

(C) Copyright by Debbie Kolozsvari 2005 


\title{
UMI Number: EC53035
}

\author{
All rights reserved \\ INFORMATION TO USERS
}

The quality of this reproduction is dependent upon the quality of the copy submitted. Broken or indistinct print, colored or poor quality illustrations and photographs, print bleed-through, substandard margins, and improper alignment can adversely affect reproduction.

In the unlikely event that the author did not send a complete manuscript and there are missing pages, these will be noted. Also, if unauthorized copyright material had to be removed, a note will indicate the deletion.

\section{$\mathrm{UMI}^{\circ}$}

UMI Microform EC53035

Copyright 2008 by ProQuest LLC

All rights reserved. This microform edition is protected against unauthorized copying under Title 17, United States Code.

ProQuest LLC

789 East Eisenhower Parkway

P.O. Box 1346

Ann Arbor, MI 48106-1346 
I hereby declare that I am the sole author of this thesis.

I authorize Ryerson University to lend this thesis to other institutions or individuals for the purpose of scholarly research.

Debbie Kodozsvari

I further authorize Ryerson University to reproduce this thesis by photocopying or by other means, in total or in part, at the request of other institutions or individuals for the purpose of scholarly research.

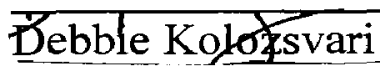


Ryerson University requires the signatures of all persons using or photocopying this thesis. Please sign below and give address and date.

\begin{tabular}{|c|c|c|}
\hline Signature of Borrower & Address & Date \\
\hline & & \\
\hline & & \\
\hline & & \\
\hline & & \\
\hline & & \\
\hline & & \\
\hline & & \\
\hline & & \\
\hline & & \\
\hline & & \\
\hline & & \\
\hline & & \\
\hline & & \\
\hline & & \\
\hline & & \\
\hline & & \\
\hline & & \\
\hline & & \\
\hline & & \\
\hline
\end{tabular}




\title{
Abstract
}

\section{Integration and Persistence of Escherichia coli O157:H7 86-24 \\ in a Naturally-Occurring Water Well Biofilm.}

\author{
Debbie Kolozsvari, M.A.Sc \\ Environmental Applied Science and Management \\ Ryerson University \\ September 2005
}

Studies to determine how a microbe can persist in a foreign environment are essential in understanding water contamination by infectious agents. Annular reactors were designed, constructed, and used as a laboratory-based model to study naturallyoccurring biofilms. Untreated groundwater was used as the bulk liquid, and a foreign microbe with a green fluorescent protein (GFP) marker was introduced. It was demonstrated that under oligotrophic conditions Escherichia coli O157:H7 86-24 did not grow planktonically. The microbe demonstrated an ability to integrate into the existing biofilm. Various environmentally-relevant concentrations of nitrogen and phosphate were also used to detect any effects on its persistence. The results suggest that the persistence of the E.coli O157:H7 86-24 was enhanced when the bulk fluid was amended to contain $100 \mathrm{ppm}$ nitrate, and hindered when phosphate was added. To utilize available molecular tools, polymerase chain reaction (PCR) coupled with denaturing high performance liquid chromatography (DHPLC) were used. It was found that the E.coli O157:H7-specific primers were not as reliable in detecting E.coli O157 within the biofilm when compared to detection using the GFP marker. PCR using 16S rRNA primers were also used to gain insight into the microbial diversity of the biofilm. 


\section{Acknowledgements}

I would like to thank the various people who helped me during my studies. First, I thank my supervisor, Dr. Steven Liss, who accepted me into his research laboratory. I would also like to thank Dr. Scott McGeorge, my previous employer, for being incredibly flexible and understanding while I worked for him part-time. He was also generous in providing the financial means which allowed me to visit Transgenomic, Inc. in Omaha, in support of my research.

I also give great thanks to Dr. George Hong and Tim McKenzie, of Transgenomic, Inc., who openly shared their research in microbiology applications using DHPLC. During my visit, both were extremely welcoming and generous with their positive words of encouragement. I am also grateful to my previous supervisor from the Hospital for Sick Children. Dr. John Vincent, who kept his lab doors open to my neverending requests for favors, and has remained a valued friend throughout the years.

I would also like to acknowledge my friend, Jim McCarron, who made the difficult task of making reactors fun, Mitsuko Kanetani, for training me on the confocal microscope, and Dr. Jian Liu, for training me on the inverted microscope.

I must also thank my parents, Mila and George Kolozsvari, who have supported my continual schooling over the seemingly endless years of study. Finally, I give great acknowledgement to my wonderful husband, Mark Marucelj. He not only told me about this program, but was unrelenting with his words of confidence and encouragement. 


\section{List of Figures}

Figure 1 A. Full-view of the two reactors constructed, and used throughout the study. B. A closer view of the reactors attached to the pump..............35

Figure 2 Biofilm strip typically found in the water/air interface of the slide.

A. Image from inverted microscope taken from a 7-day old biofilm, amended with $100 \mathrm{ppm} \mathrm{NO}_{3}$. B. Image from inverted microscope taken from an 8-day old unamended biofilm

Figure 3 A. Unamended biofilm given 11 days to develop. B. Reactor amended with $1 \mathrm{ppm}$ peptone. Both images were taken one day after E.coli 86-24GFP was added....

Figure 4

A, B. Gram stains of slide, 26 days from the start of experiment, $1 \mathrm{ppm}$ peptone. Images show various microbes: cocci, filamentous, and rodshaped bacteria.

Figure 5 A. Unamended reactor, 7 days after E.coli 86-24-GFP was added. B. Unamended reactor, 7 days after E.coli $86-24-G F P$ was added, UV

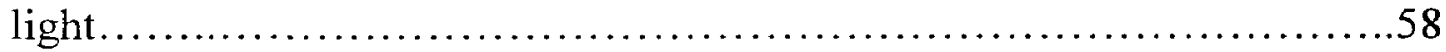

Figure $6 \quad$ Amended 1 ppm peptone, 7 days after E.coli 86-24-GFP was added. A. Image near top, under regular light. B. Same image as B, under UV light.

Figure 7 A. Reactor amended with $10 \mathrm{ppm} \mathrm{NO}_{3} .5$ days after E.coli 86-24-GFP was added. B. Same image as 10 A, under UV light.

Figure $8 \quad$ A (normal light) \& B (UV light), taken near the top of the slide, $100 \mathrm{ppm}$ $\mathrm{NO}_{3}, 5$ days after E.coli was added. C (normal light) \& D (UV light), taken near the bottom of the slide, $100 \mathrm{ppm} \mathrm{NO}_{3}, 5$ days after E.coli 8624-GFP was added.

Figure 9 A (normal light) \& B (UV light), taken near the top of the slide, $100 \mathrm{ppm}$ $\mathrm{NO}_{3}, 9$ days after E.coli 86-24-GFP added. GFP can no longer be captured for $10 \mathrm{ppm} \mathrm{NO}_{3}$-ammended reactor. 
Figure $10 \quad \mathrm{~A}$ (normal light) \& $\mathrm{B}$ (UV light). Taken 3 days after E.coli 86-24-GFP was added, $0.2 \mathrm{ppm} \mathrm{PO}_{4}$. E.coli $86-24-\mathrm{GFP}$ is clustered more closely together. C (normal light), and D (UV light), taken 5 days after E.coli 8624-GFP was added, $0.2 \mathrm{ppm} \mathrm{PO}_{4}$. The biofilm appears more developed, but the GFP is starting to fade

Figure 11 A (normal light) and B (UV light). Taken 5 days after E.coli 86-24-GFP was added, $0.2 \mathrm{ppm} \mathrm{PO}_{4}$ and $100 \mathrm{ppm} \mathrm{NO}$. E.coli 86-24-GFP appears to be doing well; however, by day 11 , GFP can no longer be imaged........65

Figure 12 A (normal light) \& B (UV light). Taken 4 days after E.coli 86-24-GFP was added, amended with $0.2 \mathrm{ppm} \mathrm{PO}_{4}$ and $10 \mathrm{ppm}$ $\mathrm{NO}_{3}$

Figure 13 A (normal light), \& B (UV light), taken 4 days after E.coli 86-24-GFP was added, amended with $0.2 \mathrm{ppm} \mathrm{PO}_{4}$ and $100 \mathrm{ppm} \mathrm{NO}_{3}$. E.coli is doing well, but is not able to adhere to the biofilm or slide near the very top. There is good biofilm growth at the very top (16C), but no E.coli 86-24GFP was found there (16D- UVlight).

Figure 14 Trial One: Graphical representation of the averaged tallies obtained in an unamended reactor, and a reactor amended with $1 \mathrm{ppm}$ peptone.

Figure 15 Trial Two: Graphical representation of the averaged tallies obtained from reactor conditions using $10 \mathrm{ppm}$ of nitrate, and $100 \mathrm{ppm}$ nitrate. .70

Figure 16 Trial Three: Graphical representation of the averaged tallies obtained from reactor conditions using $0.2 \mathrm{ppm}$ phosphate, and $10 \mathrm{ppm}$ nitrate with $0.2 \mathrm{ppm}$ phosphate.

Figure 17 Graphical representation of the averaged tallies obtained from reactor conditions using $100 \mathrm{ppm}$ of nitrate, and $100 \mathrm{ppm}$ nitrate with $0.2 \mathrm{ppm}$ phosphate

Figure 18 Figure 18: DHPLC Chromatogram obtained using O157-specific primers. The bottom trace is a size ladder available from Transgenomic, Inc......76

Figure $19 \quad$ Selected chromatograms using 16S rRNA primers......................79

Figure $20 \quad$ Selected chromatograms for $16 \mathrm{~S}$ rRNA primers.......................80 


\section{List of Tables}

Table 1 Sources of contamination in groundwater...........................24

Table 2 Reactor amendments used in survivability study.......................31

Table 3 Physical Characteristics of the annular reactor.........................36

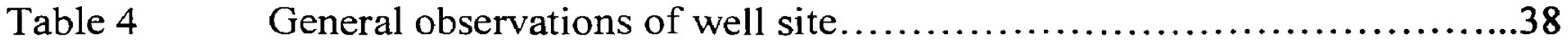

Table 5 Concentrations of various chemicals found in the bulk fluid............40

Table $6 \quad$ Experiment overview...........................................43

Table $7 \quad$ Primers used for $16 \mathrm{~S}$ rRNA PCR analysis..............................49

Table 8 Summary and comparison using O157 primers and GFP to monitor E.coli

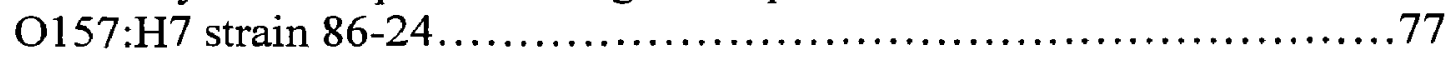


Nomenclature

$\begin{array}{ll}\text { CLSM } & \text { Confocal Laser Scanning Microscopy } \\ \text { DGGE } & \text { Denaturing Gel Gradient Electrophoresis } \\ \text { DHPLC } & \text { Denaturing High Performance Liquid Chromatography } \\ \text { DNA } & \text { Deoxyribonucleic Acid } \\ \text { EHEC } & \text { Enterohaemorrhagic Escherichia coli } \\ \text { EPS } & \text { Extrapolymeric Substances } \\ \text { GFP } & \text { Green Fluorescence Protein } \\ \text { NCBI } & \text { National Center for Biotechnology Information } \\ \text { ODWS } & \text { Ontario Drinking Water Standards } \\ \text { PCR } & \text { Polymerase Chain Reaction } \\ \text { rRNA } & \text { ribosomal ribonucleic acid } \\ \text { Stx } & \text { Shiga toxin } \\ \text { TMHA } & \text { Thermal Modulated Heteroduplex Analysis } \\ \text { UARR } & \text { Universal Amplified Ribosomal Region }\end{array}$

ix 


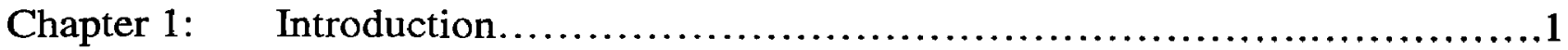

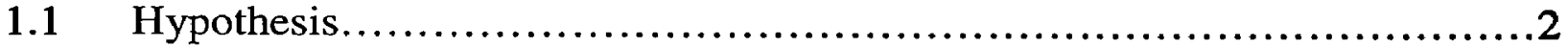

1.2 Experimental Approach ....................................................

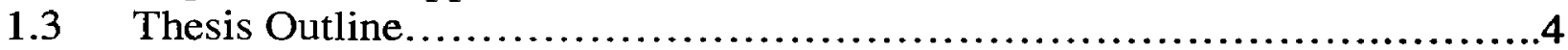

Chapter 2: $\quad$ Literature Review....................................................

2.1 Microbial Ecology .................................................... 5

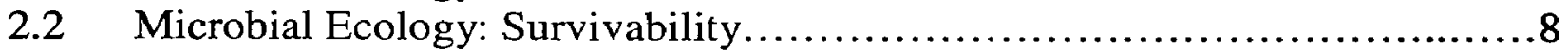

2.3 Biofilms......................................................... 10

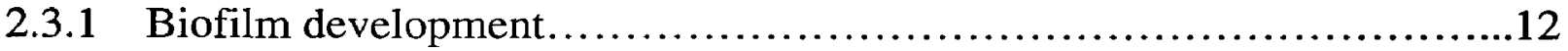

2.3.2 Extracellular polymeric substances (EPS) ............................14

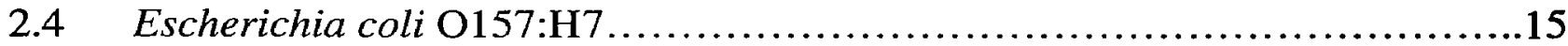

$2.5 \quad$ Escherichia coli O157:H7 Survivability ...............................18

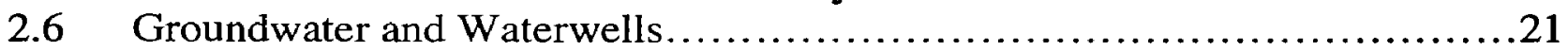

2.6.1 Nutrient Contamination: Phosphorus.................................25

2.6.2 Nutrient Contamination: Nitrogen ..................................26

2.6.3 Nitrogen levels in Canada.......................................28

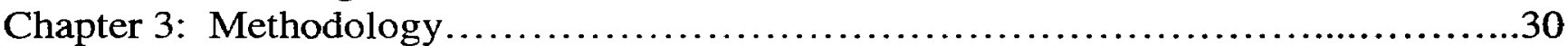

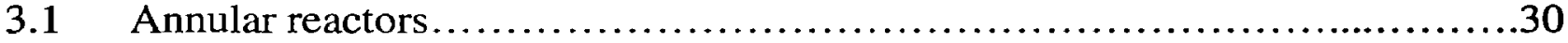

3.1.1 Annular reactor design \& conditions ................................ 34

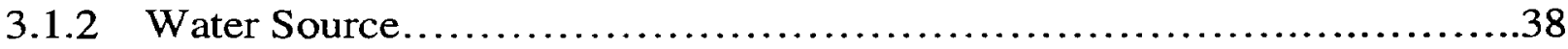

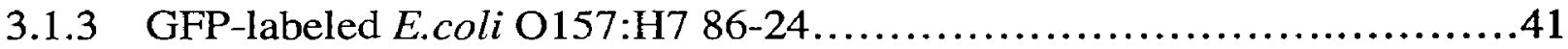

3.1.4 Experiment overview.............................................41

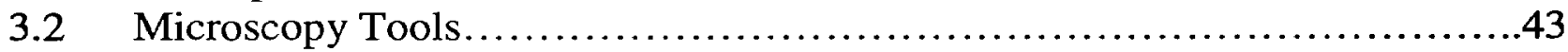

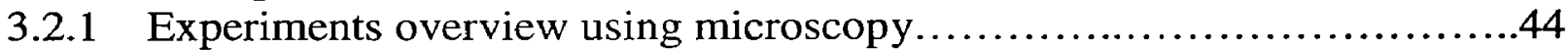

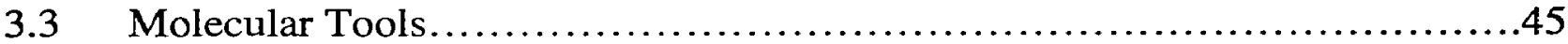

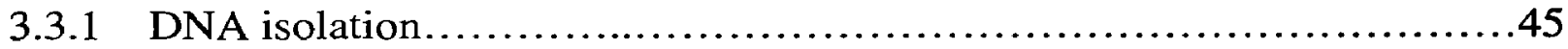

3.3.2 PCR using O157-specific primers..................................46

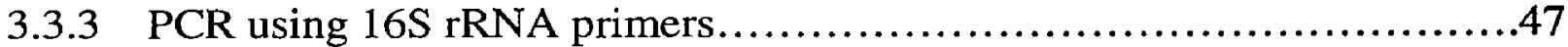

3.3.4 Denaturing High Performance Liquid Chromatography (DHPLC).........50

3.3.5 Experimental design using PCR and DHPLC.........................52

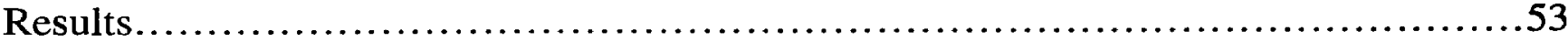

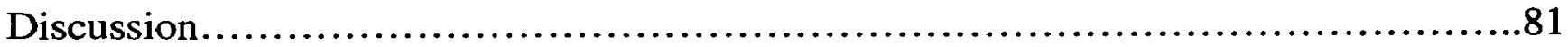

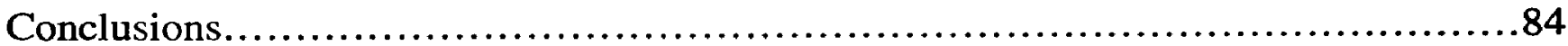

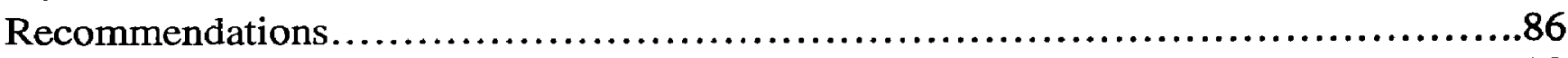

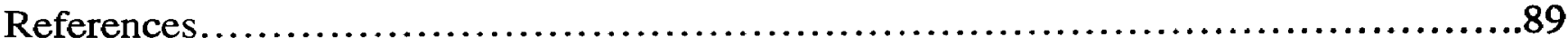




\section{Chapter 1: Introduction}

Microbes establish themselves within biofilms in the subsurface, including the interface between groundwater and a drilled-well. Microbial ecology at this site is important to understand for two main reasons. The microbes that exist here contribute to biofouling of wells. This is an important consideration particularly with respect to a well's construction and maintenance. Groundwater microbiology also plays a role in understanding the fate of various pollutants, including nutrients and pathogens. It is therefore crucial to understand what interactions might occur when such contaminants encounter these naturally-existing biofilms. This in turn can also potentially effect the microbial populations present.

In Canada, our ability to gain easy access to large amounts of freshwater has supported its widespread use for various human activities. An often noted source of water contaminants is from the waste effluent of agricultural activities (Odgen et al., 2001). Waste effluent contributes to the increasing concentrations of nutrients, such as nitrate and phosphate, which can be transported to groundwater. Areas considered at risk occur where intensive agriculture practices are located near untreated private water supplies. These changes in farming practices likely play a role in the increased exposure to pathogens such as Escherichia coli O157:H7 (Law. 2000, Odgen et al., 2001). To aid in the process of developing adequate water management practices, pathogen persistence at the groundwater/well interface should be studied. Since a pathogen, considered a foreign microbe, will come into contact with indigenous microbial populations, competition and cooperation among microbes must also be considered. 
The purpose of this study was to: (i) explore what tools are presently available and could be used to study well-water biofilms, and (ii) to gain insight into the persistence of a foreign microbe when it encounters a naturally-existing biofilm in well water. This persistence was examined under various, yet ecologically relevant concentrations of nitrate and phosphate. This was done since contaminants are increasingly being found in groundwater, and will have an impact on the dynamics of a biofilm (Biksey \& Gross, 2001, Environment Canada et. al., 2001).

\subsection{Hypothesis}

The underlying hypothesis of this study is that when a foreign microbe encounters a naturally-existing biofilm, it will be able to integrate, and persist. Nutrient concentrations will have an effect on the biofilm, and therefore impact the survivability of a foreign microbe. Generally, a higher nutrient concentration would allow the indigenous microbes to out-compete, and therefore limit foreign microbe persistence. However, small increases in nutrients, although still considered oligotrophic, will aid survivability. 


\subsection{Experimental Approach}

Annular reactors are commonly used in lab studies that require the growth of biofilms on microscope slides in a controlled environment. Since commercial reactors are expensive, annular reactors were first designed, constructed, and tested as a practical means of growing biofilms. The reactors were run using well water as the bulk fluid. Amendments were made to the source water to create slightly different nutrient environments.

A green fluorescent protein (GFP) labeled microbe, Escherichia coli O157:H7 8624 , was used as a traceable foreign microbe that could be introduced into the naturallyoccurring biofilm. This was the only enterohaemorrhagic E.coli (EHEC) O157:H7 strain that was used in the study, and will also be referred to as E.coli $86-24-G F P$. The persistence of E.coli 86-24-GFP was monitored with its GFP marker using an inverted, epifluorescence microscope, and a confocal scanning laser microscope. Slides were scraped to collect biofilm for extraction of genomic DNA and analysis using E. coli O157-specific primers. To gain insight into species diversity, 16S rRNA primers were also utilized. A relatively new technique, DHPLC (denaturing high performance liquid chromatography), was implemented to analyze the results. 


\subsection{Thesis Outline}

To test the hypothesis, four objectives were pursued:

1. To design, and construct two annular reactors to study biofilms in a laboratory.

2. To establish a naturally-occurring biofilm in an annular reactor and to introduce a traceable, foreign microbe.

3. To obtain detectable differences in survivability under ecologically relevant parameters.

4. To monitor foreign microbe survivability, and microbial diversity using a combination of microscopy and techniques in molecular biology. 


\section{Chapter 2: Literature Review}

\subsection{Microbial Ecology}

Both eukaryotic and prokaryotic microbes exist in many environments, although prokaryotes have a greater range in the subsurface. Filtration by particle size and a lack of organic matter are likely the main reasons (Maier, et al. 2000). Organisms such as Fungi, Algae, and Protozoa are part of the more complex Eukaryotes. Prokaryotes, with a simpler structure, are made up of two domains: bacteria, and archaea. Archabacteria are typically found in more extreme habitats. All of these types of bacteria tend to grow rapidly under favorable conditions. and will shrink from a typical size of 1-2 $\mu \mathrm{m}$, to less than $0.3 \mu \mathrm{m}$ in a more stressful environment. They are then referred to as ultramicrobacteria. Ultramicrobacteria are major contributors to the world's biosphere with respect to carbon, nitrogen, and phosphorus cycling (Varnam \& Evans, 2000). Bacteria are also defined based on the properties of their cell wall. Gram-positive and gram-negative bacteria are found in soil, water, and in subsurface environments (Brock and Madigan, 1991).

Two survival strategies are often employed by microbes. Copiotrophs, or rstrategists form resting stage cells, which can have sudden bursts of growth. Oligotrophs, or k-strategists, grow slowly with intermittent periods of starvation or faster growth (Ostrowski, et al. 2001). Some commonly used groups of microorganisms are autotrophs, heterotrophs, psychrophiles, thermophiles, aerobes, and anaerobes (Varnam \& Evans, 2000). 
Although prokaryotes are not as complex as eukaryotes, they are extremely diverse. The National Center for Biotechnology Information (NCBI) houses many sequence databases, including a prokaryote archive of over 30,000 species. This is an impressive collection, however recent estimates suggest the sea, for example, may contain closer to two million different bacteria. One ton of soil could contain four million different bacteria. Of the 30,000 logged bacteria, only 13,000 are formally described. Furthermore, of the forty known Divisions, ninety percent of the sequences are part of only four Divisions (NCBI website, 2004). Despite its large size, the database is clearly not a true representation of the many species that exist in nature. More work is needed to determine what microbes are indigenous in a particular environment (NCBI website, 2004).

Many studies have now demonstrated the ability to detect microbial populations from groundwater. Over a three-year study in Virginia, McKeon et al., 1995, were able to detect more than 250 coliform and non-coliform bacteria from rural, untreated wells. The microbes were collected by membrane filtration to look at the occurrence of antibiotic resistance. Some of the coliforms found included Escherichia coli, Citrobacter freundii, and Enterobacter cloacae. Non-coliforms included Acinetobacter calcoaceticus, Aeromonas hydrophila, and Serratia marcescens (McKeon et al., 1995). Bacterial diversity can be determined experimentally using $16 \mathrm{~S}$ rRNA genes. Microbial diversity in surface waters, groundwater, wastewater plants, and even bottled water, has been examined (Ovreas, et al., 1997., Watanabe, et al., $2000 \&$ 2001, Boon et al., 2002., Dewettinck, et al., 2001). These genes are used to identify both culturable and unculturable bacteria, because they are analyzed by amplifying fragments of microbial 
genomic DNA rather than by selective culturing. The 16S rRNA genes are used because they are crucial for protein translation. This makes them well conserved overall, but with some variation between different species. DNA from environmental samples is used as the template to amplify a region of the gene. The sequences obtained can then compared to any existing sequence databases. such as the GenBank database from NCBI. A new sequence found in this manner will be listed as 'uncultured bacterium' since it must be isolated and cultured for further characterization. The sequence information can also be entered into software that clusters the represented bacteria based on the similarity of sequences. There are a large number of studies that have used a combination of denaturing gradient gel electrophoresis (DGGE) with 16S rRNA primers as a means of determining the species present in a population of microbes. As an example, Ibekwe et al., 2003 used DGGE and 16S rRNA, to look at the bacteria community present in constructed wetlands and manure. Using this technique, they were able to determine that the dominant bacteria in their samples was related to Bacillus, Clostridium, Mycoplasma, Eubacterium, and Proteobacteria, which are also found in the gastrointestinal tracts of mammals. They also found that a higher percentage of Nitrospira-like sequences were found in the wetlands, compared with Nitrosomonas-like sequences in the manure, as well as, in feces and raw washwater (Ibekwe et al., 2003). 


\subsection{Microbial Ecology: Survivability}

Prokaryotes have the widest range of conditions in which they can survive. This persistence is due to great metabolic versatility, and phenotypic plasticity. Microbes are able to adapt when a new niche presents itself (Davey and O'Toole, 2000). Fossil records indicate that a long-used method of enhancing survivability in various environments has been the formation of biofilms (Hall-Stoodley et al., 2004). This is especially true for nonendospore-forming bacteria. A biofilm lifestyle is so ubiquitous, it is likely the essential characteristic in which bacteria persist (Davey and O'Toole, 2000). Bacteria would only exist outside of a biofilm if it had been sloughed off and was in transit to another biofilm. Considering that biofilms are physiologically different than plankontic bacteria, our knowledge of microbes is therefore limited. Biofilm persistence is due to changes in phenotype, inactivation by extracellular polymers or modifying enzymes, or nutrient limitation which slows growth rate (Davey and O'Toole, 2000).

Natural environments usually have a diverse population of microbes. They develop in spatially organized physicochemical gradients. In low nutrient levels, biofilms are a few micrometers thick, and will be organized vertically or horizontally depending on the gradient. Many conflicting lifestyles can grow in close proximity. This allows the microbes to obtain some of the benefits of multicellular life. Cometabolism, cross-feeding, and protection from disasters all lead to long-term stability. Adaptation has been considered a trait only seen in gram-negative bacteria, but some gram-positive have also displayed this ability (Varnam \& Evans, 2000, Maier et al., 2000). 
Competition in biofilms is an interesting area of study. In 1964, W.D. Hamilton first proposed the theory of kin selection as an altruistic cooperative behavior. By helping relatives, this would help the species to proliferate as a whole. A study by Griffin et al., 2004, studied this possibility in bacteria. They found that when Pseudomonas aeruginosa produced siderophores. molecules excreted to scavenge iron, it proliferated when it was grown in a biofilm where there was a high degree of relatedness. They did not proliferate when there was a low degree of relatedness. This suggests that the bacteria are willing to expend the energy and allow other bacteria to utilize the benefits of its actions more so when they are more closely related. However, eventually these closest neighbors would also become the main competition, where the altruistic behavior would cease (Griffin et al., 2004). Therefore, the scale of the competition must be considered.

When the extreme diversity of the natural environment is considered, it is a daunting task to gain insight into such unmatched diversity found among other living organisms. Growth of some microorganisms can be easily achieved when placed in a nutrient rich medium where they can begin dividing within ten minutes. Cell division in subsurface environments could, however, take up to 100 years due the nutrient poor, and heterogeneous conditions (Varnam \& Evans, 2000). Understanding how a pathogen survives is very difficult considering the extreme complexity and various factors making up these microenvironments. 


\subsection{Biofilms}

Biofilm is a sessile community of microbes. It is characterized by its attachment to a solid surface, where it is embedded in extracellular polymeric substances (EPS). EPS is a key, and hence well-studied, component of the biofilm. It is discussed in greater detail in Section 2.3.2. Bacteria, fungi, metabolic byproducts, clay, and soil are all possible components comprising a biofilm. Biofilm is also characterized by a distinct change in phenotype with respect to growth, gene expression, and protein production (Shirliff et al., 2002). In fact, Sauer et al., 2002, demonstrated that Pseudomonas aeruginosa has multiple phenotypes during biofilm development. The net result is a complex structure of microcolonies with a network of channels allowing the passage of nutrients (Johnston, 2004, Shirtliff et.al., 2002, Sauer et al., 2002).

In an environment where nutrients are not abundant, bacteria benefit significantly if they form a biofilm (White et al., 1999). Other factors that usually limit bacterial survival are a lack of oxygen, as well as competitive, antagonistic, and predatory activities of indigenous populations. The biofilm will capture and concentrate nutrients, including carbon, nitrogen, and phosphate. Biofilms also offer protection against antimicrobial factors. This may be due to the reduced metabolic levels, and downregulated rates of cell division. It also prevents certain chemicals from entering into the biofilm by acting as an ion exchanger. This is especially pronounced for hydrophilic, positively-charged antibiotics (Davey \& O'Toole, 2000, Shirtliff et al., 2002).

The environmental conditions also play a large role in shaping the biofilm structure. Examples include substratum properties, nutrient availability, community 
composition, and hydrodynamics of the bulk fluid. In areas of high shear stress, biofilms tend to be stratified and compact. Biofilms under laminar flow are found to be patchy, with rough round cell aggregates spaced by interstitial voids. Turbulent flows also have patchy growth, and will have elongated streamers in the flow (Davey and O'Toole, 2000). High nutrient levels affect the biofilm by allowing a rapid increase in thickness, but the overall film stability may be reduced. The density of a biofilm tends to increase with the direction of the flow. With age. biofilms become denser suggesting that existing pores and channels inside the biofilm decrease as the biofilm ages. Nutrient diffusion through biofilms tends to be slow where only limited amounts reach the deeper layers (Varman \& Evans, 2000).

Biofilms are dynamic: cells peel away (usually the more hydrophilic cells), and provide a supply of inoculum for the development of biofilms elsewhere. This can occur as a result of fluid shearing, or due to a genetically programmed response that directs the detachment process (Shirtliff et al., 2002). Despite sloughing off, biofilms usually become thicker over time. The quiescent cells, which are oligotrophs, will fair better in the lower layers. However, if the film does become too thick, even the well adapted microbes will die, causing fragility, and sloughing off (Shirtliff et al., 2002).

Direct observation of microbial populations and biological activity is needed to provide information on population dynamics, and metabolic processes. Confocal scanning laser microscopy (CLSM) has been commonly used to study the development and structure of biofilms in a nondestructive manner. Numerical information about biofilm morphology can be accomplished with digital processing. Green fluorescent protein (GFP) has also been used with success as a reporter protein for gene expression 
(Lowder et al., 2000). Having such tools is necessary to understand the complexity of biofilms. Biofilms have been implicated as the primary cause of biological contamination in drinking water distribution systems. Some recent studies have also proposed that biofilms in groundwater provide favorable conditions for pathogens introduced into the subsurface, however there is little experimental data on the conditions in which biofilms provide protections for pathogens, and the extent to which this may occur (Banning et al., 2003).

\subsubsection{Biofilm development}

Surfaces in contact with liquid will develop a conditioning film within seconds. This may only be a film that has a thickness measured in nanometers, and the properties of the film will affect subsequent biofilm formation. Colonization to a 'clean' surface is called the primary biofilm, and their progeny is called the secondary biofilm. Primary cells experience a lag in their growth possibly due to its adaptation to a sessile environment, and also due to phenotypic changes (Johnston, 2004, Shirtliff et al., 2002).

Biofilm formation occurs in the natural environment and in living tissues. A fundamental difference in biofilm formation in the environment is that it is non-specific, whereas in living tissues it is specific. This non-specificity, however, may not be that straightforward. In Stewart et al's 1995 study, they found biofilm to be several hundred microns thick in some places, and bare substratum in others. Staining of cells with ethidium bromide, and EPS with calcufluor showed that some cell-free areas were filled 
with EPS. The exact reasons why some areas of the same substratum are occupied and other are not, is not understood (Johnston, 2003).

Biofilm begins to develop when various molecules absorb at a liquid/solid interface. These molecules may include proteins, polysaccharides, humic acids, and fatty acids and lipids. This conditioning film will then have an effect on surface hydrophobicity and charge. In this early stage. microbial colonization will largely depend on transport from the bulk fluid. Once transported to the site of attachment, adherence will depend on surface properties, the physiological state of the microbes, and hydrodynamics near the surface (Bandfield \& Nealson, 1997). Adhesion may be affected by cell appendages, or excretion of adhesives (Scheuerman et al., 1998). When compared with planktonic bacteria, surface-induced gene expression is markedly different. This is likely because the formation of a biofilm requires coordination (communication and interactions) among various bacterial species. The bacteria begin to orient themselves, and cluster (Davey and O'Toole, 2000).

When the cell cluster reaches a thickness of approximately $10 \mathrm{um}$, it is considered mature. At this stage the biofilm may also be dispersed if it begins to slough off. The cluster structure changes with the development of pores and channels, and both motile and nonmotile forms of the microbes will be present. The protein profile at this stage more closely resembles that of planktonic bacteria. When the protein profile in a biofilm was examined, over 800 proteins, or over $50 \%$ of the proteome, had a sixfold or greater expression level. An important transcriptional regulator that turns on antibiotic resistance (by inducing transcription of efflux pumps) was among the upregulated genes (Davey and O'Toole, 2000). Rate of colonization varies, and the stability may take hours to months 
to develop (Varnman \& Evans, 2002). Rice et al., 2000, looked at growth rates in biofilms. They found that planktonic and secondary biofilm cells grew faster than the primary biofilm cells when exposed to the same nutrient conditions. The parent cells were able to form dense microcolonies that could disperse within minutes. The daughter cells were found tightly packed, spread out, rolling, forming chains, or becoming detached. How the daughter cells form was likely determined by species, but also influenced by environmental conditions (Rice et al., 2000).

\subsubsection{Extracellular polymeric substances (EPS)}

Bacteria produce wall polysaccharides (capsules), or excreted polysaccharides. These excreted substances provide the backbone of the biofilm. The polysachharides that usually make up the EPS are rhamnose, galactose, glucosamine, galacturonic acid, or hyaluronic acid. Polypeptides or cellulose can also make up the EPS. The EPS is bound by electrostatic interactions with the outer wall polymers. With exceptions, EPS is released at the end of the exponential growth phase, or during the stationary (starvation) phase, and favors adhesion to hydrophobic surfaces. This has been seen in marine environments where small cells (associated with starvation) are seen to first adhere to a surface (Varnam \& Evans, 2002). The presence of nutrients and minerals caught in the biofilm give the biofilm a net negative charge on the matrix. Flagella, pili, fimbria, and EPS are the main means of microbes interacting with their environment (Hoppert, 2003). It provides a close proximity for horizontal gene transfer. This may occur between bacteria by conjugation, or by infection of bacteriophages. It has been estimated that $10-$ 
$20 \%$ of the bacterial population are lysed daily by bacteriophages (Davey and O'Toole, 2000). EPS protects cells from environmental stresses, such as sudden changes in $\mathrm{pH}$, water content, and antibiotic agents. In a less stressful environment, such as that experienced by lab strains, the ability to produce EPS may be lost entirely (Davey and O'Toole, 2000).

\section{$2.4 \quad$ Escherichia coli $\mathrm{O} 157: \mathrm{H} 7$}

Escherichia coli are found in the human body as a facultative anaerobe found in the human intestinal tract. The specific reasons as to why it is successful here is unknown, however its ability to utilize gluconate in the colon, might give it a unique niche. A relatively recently described pathogen found in freshwater is the strain E.coli 0157:H7, an EHEC. It was after two outbreaks in 1985 that E. coli $\mathrm{O} 157$ was recognized as a human enteric pathogen. The earliest probable case was first recorded in 1975, although it may have also been the cause of some diarrheal outbreaks in the United States during the 1950s (Law, 2000). EHEC causes haemorrhagic colitis (bloody diarrhea), and haemolytic uremic syndrome (HUS). The main reservoir for EHEC is in the bovine intestinal tract. It is very infectious where the dose can be as low as 10 to 100 cells (Hayashi et al., 2001). E. coli O157 has now been studied extensively in the food industry to better understand how it can potentially infect humans due to its persistence in various types of food.

In 2000, an outbreak occurred in Walkerton, Ontario. This again demonstrated the potential for serious and lethal infection of E.coli $\mathrm{O} 157$ from untreated water. As a 
result, recent studies have begun to assess the transport and persistence of $E$. coli O157:H7 and other pathogens in groundwater. The Walkerton tragedy lost seven people to E.coli $\mathrm{O} 157: \mathrm{H} 7$ when the town's drinking water was not properly treated with chlorine. A further 2,000 individuals also became ill during the outbreak. As a result, the site was extensively tested and thoroughly cleaned before the water was considered safe to drink. It was determined that a spring rainstorm washed E.coli $\mathrm{O} 157: \mathrm{H} 7$ into a poorly planned and maintained town well (well 5). The rainfall event occurred on May 12, 2000, and five days later, on May 19,2000, the first symptoms of bloody diarrhea, vomiting, cramps, and fever occurred. Incompetent water managers combined with government downsizing were the main factors leading to the disaster (Websource: www.ene.gov.on.ca/envision/techdocs/4000e $01 . \mathrm{htm})$. The results of phenotypic and molecular typing supported the hypothesis that the municipal water supply was contaminated by a farm. Waste from a farm entered well 5 where E.coli $\mathrm{O} 157: \mathrm{H} 7$ gained access to the well and then into the water distribution system. Well 5 was later decommissioned (Clark et al. 2003).

As a result of the Walkerton E.coli $\mathrm{O} 157: \mathrm{H} 7$ outbreak, two major reports were produced by the Ministry of Environment, prepared by the Honourable Dennis R. O'Connor. New well regulations went into effect in August 2003, but still did not meet the Walkerton inquiry recommendations. Some specific concerns were that: (i) the standards for disinfecting wells with chlorine was lowered, (ii) there were no requirements to clean newly drilled wells, (iii) no requirement to seal water line connections, and (vi) contractors could construct wells with used well materials (Websource: www.nupge.ca/news_2003/n12au03b.htm). 
Twenty-one recommendations from the first report have now been implemented, and the remaining seven are still underway. The second Walkerton report made 93 recommendations, and that an additional 49 million dollars be spent each year to ensure safe water in Ontario. As of May 2005, 39 recommendations have been implemented, 28 are being implemented through legislation. and 26 are still underway (Websource: www.ene.gov.on.ca/envision/water/sdwa/status_part2.htm, www.ene.gov.on.ca/envision/water/sdwa/status_part1.htm).

E.coli $\mathrm{O} 157: \mathrm{H} 7$ is unique from other E.coli in that it produces the Shiga toxin (Stx). The shiga toxin is a verocytotoxin (VT) which ultimately cleaves rRNA, effectively preventing protein synthesis (Kaper et al., 2004). Many serotypes of EHEC have now been identified. One strain of E.coli $\mathrm{O} 157: \mathrm{H} 7$ was isolated by researchers in Japan and its sequence was compared to the benign laboratory strain E. coli $\mathrm{K}-12$. They found that E. coli O157's genomic DNA was 5.5 megabases (Mb), or 859 kilobases (Kb) larger than E.coli $\mathrm{K}-12$. Most of the DNA common to both bacteria was highly conserved. The remaining was made of O157-specific sequences (Hayashi et al. 2001). Several genes responsible for the production of $0157^{\prime}$ s toxin production are encoded on a plasmid. Overall, it was found that E.coli $\mathrm{O} 157: \mathrm{H} 7$ had 1632 proteins and $20 \mathrm{tRNAs}$ not found in $\mathrm{K}-12$, where 131 of the proteins are thought to contribute to its virulence (Hayashi et al. 200).

The Shiga toxin was probably acquired during plasmid transfer through a bacteriophage from Shigella dysenteriae. Bacteriophages appear to have played a role since 24 prophages and prophage-like elements were found in more than half of the O157-specific sequences (Hayashi et al. 200). The toxin is identical to the Shigella toxin 
that causes dysentery. It has been proposed that there might have been a selective pressure for E.coli $\mathrm{O} 157: \mathrm{H} 7$ to maintain this plasmid, because it could help defend itself from attack by amoebas (Websource: http://exn.ca/stories/2000/06/07/53.asp).

\subsection{Escherichia coli O157:H7 Survivability}

E.coli $\mathrm{O} 157: \mathrm{H7}$ has been shown to be culturable for days to weeks from various sources, including water samples (Porter et al., 1997). Microbes in the natural environment will be exposed to a variety of stresses. To persist, they must be able to survive changing conditions. Various conditions may enhance the growth of particular microbes giving them a competitive advantage over other microbes. Less adapted microbes will either die off, or go into a hibernation state until conditions become more favorable to growth. These microcosms are always dynamic and changing. Survival rate of E.coli $\mathrm{O} 157: \mathrm{H} 7$ from manure applied to farmland, has been shown to decrease at higher temperatures $\left(15^{\circ} \mathrm{C}\right)$, and a low moisture content (Odgen et al., 2001). In a food study on seasonings, bacterial growth was suppressed with low water activity, but E.coli O157:H7 strains were found to be tolerant of such conditions (Yokoigawa et al., 1999). Understanding how pathogens might survive in the subsurface is difficult to determine. Pathogens that obtain their required nutrients with the smallest amount of energy expended are considered the most highly evolved or adapted (Baron, 1996). E.coli O157:H7 has been reported to only form a biofilm in low-nutrient conditions (Davey and O’Toole, 2000). 
Studies have shown that a heavy rainfall event is the primary means by which E.coli $\mathrm{O} 157: \mathrm{H} 7$ will be vertically transported into soil. Tillage practice, soil type, and method of pathogen delivery can affect, but ultimately do not prevent vertical coliform transport in soil. Observations made in a study by Gagliardi and Karns in 2000, suggested that soluble nitrogen could enhance transport (Ibekwe et al., 2003, Gagliardi \& Karns, 2000, Odgen et al., 2001). The source of E.coli $\mathrm{O} 157: \mathrm{H} 7$ in cattle is not wellestablished, but one possibility is cattle feed contaminated by fecal matter. There are studies now underway attempting to gain insight into both transport of E.coli $\mathrm{O} 157: \mathrm{H} 7$, and its persistence in animal and human foods. For example, a study by Dodd et al., 2002, found that in feed, E.coli O157:H7 concentrations were higher if there was an increase in lactate concentration, a decrease in propionate. or a higher $\mathrm{pH}$. Their work also showed that survival of E.coli O157:H7 in feces was considered long, and that the microbe is also likely to survive in water troughs (Dodd ef al., 2002).

The fate of a pathogen in soils and aquifers is governed by its transport and persistence into the environment. Persistence and transport is also controlled by climate, type of soil/aquifer, properties of pore fluids, and type of pathogen. For example, the negative charge on bacterial cells and the size of the pores they encounter, influence its interaction with its environment. Enteric bacterial survival in soil has been studied for a number of years, and it has been observed that their persistence is increased by lower temperatures, high soil moisture content, and abundant organic matter. Persistence is decreased in more acidic soils, and a high exposure to sunlight. A pathogen must also deal with competition and antagonism from other bacteria, as well as predation by protozoa (Mitchell, 1992). 
A small number of studies have been performed both in the field and lab, to examine microbial persistence. The persistence of E.coli O157:H7 and Psuedomonas aeruginosa in groundwater was examined in a laboratory system by Banning et al., 2003. Their hypothesis was that groundwater-derived biofilms may act as a reservoir for coliform and pathogenic bacteria. A GFP-labeled E. coli O157:H7 was used and found to colonize all layers of a mixed-population biofilm developed using groundwater microbes. Their data suggest that an increase in available nutrients could reduce $E$. coli $\mathrm{O} 157: \mathrm{H} 7$ 's survival potential due to enhanced competition or enhanced antagonism by the microbial population (Banning et al., 2003).

Few field studies have been conducted with respect to E.coli's survivability in well water. Survival of E.coli $\mathrm{O} 157: \mathrm{H} 7$ was examined in private drinking water wells in Scotland. This study, by Artz and Killham, 2002, looked at E.coli O157:H7's ability to survive under different heavy metal contents, nutrient, and bacterial grazer concentrations. They found its survival mainly decreased with increasing copper concentrations. This in combination with high protozoan counts had the greatest negative effect on survival time, suggesting that higher quality water would actually allow longer survival times for E. coli O157 (Artz \& Killham, 2002). The effect of copper is interesting as it is a commonly used material: it can result from leaching of corroding pipes, and extensive use of sewage sludge as a soil amendment (Artz \& Killham, 2002).

Lab studies using annular reactors are numerous, and some of these have studied coliforms in biofilms. A study by Camper et al., 1996 operated annular reactors using oligotrophic conditions to look at the influence of growth conditions and substratum on long-term persistence of coliforms in mixed-population biofilms. In their 8-week 
experiments, they found that larger numbers occurred when mild steel was used instead of polycarbonate. They also found that slowly grown coliforms survived at the highest concentrations (Camper et al., 1996). The lowest initial growth rate of $0.05 / \mathrm{h}$ enabled the coliforms to compete with biofilms already present. This success was likely due to the acclimatization to low-nutrient conditions (Camper et al.. 1996).

It is clear that there are many factors influencing what will be present in groundwater. Each private well would need to be accessed individually to determine its particular potential for allowing E.coli $\mathrm{O} 157: \mathrm{H} 7$ to persist. In general however, it seems that current literature suggests oligotrophic conditions help E.coli $\mathrm{O} 157: \mathrm{H} 7$ to persist in the subsurface environment, and eutrophic conditions give natural microbial populations a competitive advantage over the pathogen.

\subsection{Groundwater and Waterwells}

The subsurface environment is extremely heterogeneous, but some general comments can be made. The saturated zone, beneath the vadose zone, is considered oligotrophic, where the organic carbon content is less than $0.1 \%$. Many types of aquifers in the subsurface exist. Shallow aquifers are recharged by rainfall or rivers, and typically have a high flow rate. Intermediate aquifers are within 300 meters of the surface, and have slower flow rates. Deep aquifers are not directly recharged by rain and have the slowest flow rates. Shallow aquifers tend to be aerobic, as faster flow rates tend to increase the amount of oxygen present (Varnam \& Evans, 2000). Another consideration 
is the material in which the groundwater is found. Some may be in loose sand or gravel, or within rock materials. The usefulness of groundwater for human use is determined by its recharge and storage capacity (Nuzman, 1978).

Groundwater is accessed by drilling a well. A well experiences its best condition when it has first been drilled. Natural processes will then degrade the well over time (Nuzman, 1978). Therefore, it is necessary for wells to be properly protected when it is being used and then properly decommissioned to protect the groundwater from direct contamination by the surface. This direct access to the surface can provide a quick route for groundwater to become contaminated. An important component in well construction is the well screen that is sometimes placed at the location where water is drawn into the well. Its role is to help prevent clogging, and maintain an acceptable flow into the well. A good understanding of the aquifer permeability will determine this optimum screen velocity (Nuzman, 1978). The well will then create the environment where biofilms will begin to develop. Since wells vary depending on the type drilled, and other factors already mentioned, it is again difficult to determine the specific environmental conditions in this region and how it might affect the types of microbes that exist there.

Rainwater is often a source of recharge for groundwater. Rain usually has a pH of 5.4 , and therefore considered a weak carbonic acid solution. Once it hits the ground, various materials will be absorbed. The water then continues through the soil, developing a migration path until it finds its way into an aquifer. During its transport, water will dissolve some of the minerals in which it makes contact. In this manner, groundwater will then contain soluble iron as the water makes its way through clay. Depending on how long the water stays in the soil, it might also dissolve organics 
(Nuzman, 1978). In areas where fertilizers are used, and if the soil is oxygen rich, nitrates can also become dissolved and build up in groundwater. If the water comes into contact with limestone or shale, calcium will be dissolved. When low pressure is created in the well due to pumping, carbon dioxide will then be released, which causes calcium bicarbonate to precipitate into calcium carbonate. Iron can also precipitate around the well screen. Overall this will cause a loss of permeability and a decrease in well efficiency. If iron bacteria begin to grow, they too can clog the well screen further reducing the productivity of the well (Nuzman, 1978).

Groundwater contamination occurs when various substances enter the subsurface as a result of human activities. When this happens, the contaminants are likely to spread. This is particularly true when contaminants reach sand or gravel aquifers. For example, in Ville Mercier, Quebec, some industries had disposed of its waste into sandy lagoons subsequently contaminating the groundwater used by thousands of residents (Environment Canada et al.. 2001). Not only is cleanup of such a site difficult, but it also complicates our understanding of where these contaminants may be transported. Contamination can come from point and non-point sources (Table 1). The overall extent of groundwater contamination is very poorly understood. and an understanding is typically not sought for an area unless its users become ill. There are various examples across Canada, including the example above in Ville Mercier in Quebec, pesticides in the prairies, industry effects in Elmira, and salt from deicing in Nova Scotia. It is expected that the discovery of contaminated aquifers will increase over the coming decades. This is a serious concern because once contaminated, the aquifer will likely remain that way for decades longer. Resident times of contaminants are anywhere from two weeks to 
10,000 years. Since groundwater is part of the hydrologic cycle, it can be expected that the contamination in one area will to spread into another. Protection by groundwater management is important, but will be limited by our lack of understanding in groundwater behavior including microbial ecology at this site (Environment Canada et. $a l ., 2001)$.

Table: 1 . Sources of contamination in groundwater.

\begin{tabular}{|c|c|}
\hline Non-point Sources & Point sources \\
\hline Fertilizers & Leaky tanks or pipelines containing gas \\
\hline Pesticides on agricultural land and forests & Underground injection wells (industrial) \\
\hline Contaminants in rain, snow & Municipal landfills \\
\hline & Livestock wastes \\
\hline & Leaky sewer lines \\
\hline & Mill tailings \\
\hline & Fly ash from Coal plants (emitting flue) \\
\hline & Graveyards \\
\hline
\end{tabular}

Microorganisms are found in the subsurface. Population densities in groundwater are estimated to be between $105-107$ cells per gram dry weight (gdw). This is small when compared to microbial counts in the soil and unsaturated zone, but expected since 
the concentration of organic matter is lower in groundwater. Microbial counts do not necessarily decrease with depth. There is great variability vertically and laterally. For example, more bacteria are found in sandy sediments than clay sediments. This is likely due to the more difficult movement of both microbes and dissolved nutrients through clay (Schwartz \& Zhang, 2003).

\subsubsection{Nutrient Contamination: Phosphorus}

Phosphorus is one of the least mobile of nutrients found in soil. The negative charge on the phosphate ion forms insoluble compounds with positive ions in the upper soil (aluminum and iron in acid soils, and calcium in basic soils). Furthermore,

phosphorus will be absorbed to clay colloids and organic matter in the soil (Loehr, 1974). However, if heavy rainfall occurs, phosphate may not have time to mineralize. Under anaerobic conditions, the reductions of iron to ferrous salts may act to increase phosphorus mobility. Some studies have shown this, as well as further mobility if the soil is sandy. The Lake Erie basin has a high amount of sandy soils. Such conditions could allow phosphorus to reach groundwater (Loehr, 1974). Shallow soils, and fractured structure of limestone will also facilitate movement of percolates to groundwater (Loehr, 1974). North American guidelines recommend that phosphate (ortho, $\mathrm{PO}_{4}$ ) should not be more than $0.2 \mathrm{mg} / \mathrm{L}$, a concentration which reduces the eutrophication of water (Websource: http://www.pscanalytical.com/tech/qualityguide.asp). 


\subsubsection{Nutrient Contamination: Nitrogen}

Nitrate, unlike phosphorus, is very soluble in water, and therefore very mobile within soil solution (Cepuder \& Shukla, 2002). Nitrogen forms the readily exchangeable ammonium ion. An exception to this is if the ammonium ion is absorbed to clay minerals such as vermiculite, illite, and/or montmorillonite, all of which have a high affinity for $\mathrm{NH}_{4}$. If in solution, ammonium can be volatized as gaseous ammonia, or undergo nitrification to form the highly mobile nitrate ion (Loehr, 1974). Nitrosomonas and Nitrosococcus are involved in the first step, converting ammonia to nitrite. Nitrobacter are involved in the second step, converting nitrite to nitrate. This is inhibited in acidic soils, and at temperatures below $4^{\circ} \mathrm{C}$ (Loehr, 1974).

The Ontario Drinking Water Standard (ODWS) for ammonia is $0.1 \mathrm{mg} / \mathrm{L}$ in groundwater (Ontario Regulation 169/03). Concentrations above this value indicate that contamination has occurred. Ammonia is also sometimes corrosive to copper and its alloys, which may corrode pipes. Nitrogen as nitrate, $\mathrm{NO}_{3}{ }^{-}$, is the most common form. It exists in oxic conditions with a redox potential (Eh) that is greater than $+200 \mathrm{mV}$. Nitrates might encourage bacterial growth, which could in turn increase biofouling. Levels above $13 \mathrm{mg} / \mathrm{L}$ have been observed to cause well-related problems (Borch et al., 1993).

Application of animal manure has been used as a means of recycling nitrogen and phosphorus back into the land. The manure will also contain bacteria, including various pathogens. (Odgen et al., 2001, Gagliarni \& Karns, 2000). Higher nitrate levels in groundwater have been found near agriculture (Kemp \& Dodds, 2001). In the UK, 
research to understand how agricultural practices affect groundwater has increased, and nitrate is a particular concern. One study by Withers et al. 1997 looked at lagoon storage of cow slurry, and how effective they are at self-sealing. The lagoon was monitored from 1975 to 1982 . They found that up to $1978, \mathrm{NO}_{3}$ remained steady at $5 \mathrm{mg} / \mathrm{L}$ (only fluctuating with season and water table levels). There were then sudden spikes in all nutrients in January 1979. January 1981. and September 1981. Nitrate levels were always found between $0-17 \mathrm{ppm}$. and phosphate between $0-10 \mathrm{ppm}$. The large increases in nutrient concentrations also coincided with the occurrence of E.coli in the samples. The general conclusions of the study were that groundwater beneath the lagoon was polluted and that the self-sealing layer did not persist. Wastewater from intense agricultural activities generally have higher nutrient concentrations, and organic matter than municipal effluent (Ibekwe et al.. 2003). This can contribute to water management problems. Constructed wetlands are used to improve water quality by utilizing bacterial degradation, however in this study, only moderate removal of total nitrogen and phosphorus was detected. The use of such a natural system depends on developing a healthy microbial community for optimal wastewater treatment (Ibekwe et al., 2003). Certain microbial groups in animal waste are responsible for the breakdown of organic compounds, and for the suppression of pathogens (Ibekwe et al., 2003). Diversity of microbes in a wetland environment may be critical for proper functioning and maintenance of the system. 


\subsubsection{Nitrogen levels in Canada}

Seventy-five percent of all Canadians use water from municipal sewer systems. In $1999,97 \%$ of this group had some type of waste treatment. The remaining $3 \%$ had no treatment at all. The remaining $25 \%$ of Canadians use private wells and septic systems that are designed for rural settings. Some rural areas are now being developed into subdivisions, and far more individual wells are being installed to supply high population densities. This could endanger the ability of the aquifer to sustain itself. With poorly maintained septic systems, a pollution problem is far more likely to occur. Once contaminated groundwater spreads to rivers and lakes, this could turn into a greater water supply problem. (Websource: www.canadianenvironmental.com, www.ec.gc.ca/water/en/manage/poll/e_howgrd.htm)

With the exception of British Columbia and the Territories, $90 \%$ of rural domestic and water consumed by livestock is from groundwater. The Canadian Government has been monitoring rural wells to look at nutrient levels in the groundwater, and the data was presented in a report: Nutrients in the Canadian environment (Environment Canada et. al., 2001). Canada has a large and diverse land, so different concentrations are expected. In the prairies, dry climate and clay texture should minimize nutrient transport to groundwater. The nitrate levels in Alberta are also low, but this is likely due to fact that it has few shallow aquifers. Since Saskatchewan has many shallow and unconfined aquifers, contamination is more likely. The results showed that, in Alberta only $4-6 \%$ of

domestic wells had nitrate levels above the ODWS of $10 \mathrm{ppm}$. In Saskatchewan, $60 \%$ of farm wells, and $36 \%$ of private wells had nitrate levels exceeding 10ppm. Furthermore, 
most of the wells with elevated nitrate were close to cattle and/or poultry farms. In Quebec, one set of results found an area with intensive potato farming to have $63.6 \%$ of the 33 domestic wells sampled to exceed the limit. Similar findings were found in Atlantic Provinces, where $13-40 \%$ of wells were above $10 \mathrm{ppm}$ nitrate, with a dependency on season, and proximity to farming operations. Overall, regional surveys are found nitrate to exceed $10 \mathrm{ppm}$ the guideline anywhere from $1.5-60 \%$ in the wells tested (Environment Canada et al., 2001). 


\section{Chapter 3: Methodology}

\subsection{Annular reactors}

A wide variety of annular reactors have been used in biofilm studies (Butterfield, et al., 2002, Camper et al., 1996, Banning, et al., 2003). The first objective in this study was to determine if annular reactors, could be constructed and be successfully used to study biofilms. Microbes naturally existing in groundwater were expected to form a biofilm into which the foreign microbe would be introduced. The introduced microbe was a GFP-labeled E.coli O157:H7 86-24, which could be easily monitored. The GFP label served as a marker proven to remain stable in viable, and viable but non-culturable microbes (Lower et al., 2000). GFP requires the presence of oxygen, but labeled cells grown under anaerobic conditions will develop fluorescence upon exposure to air (Banning et al., 2003). The reactors used were not uniformly aerated, but could be considered aerobic overall since no attempts were made to create an anaerobic environment. GFP plasmids have been suitable cellular markers, but not necessarily viability indicators for use under non-selective, anaerobic, or nutrient-limited conditions. Since the use of GFP as a viability indicator in nutrient-limited conditions was a concern, PCR using E.coli O157-specific primers was also performed on all samples collected in each experiment. This was then compared to the results obtained from monitoring E.coli O157:H7 86-24 by microscopy. The survivability of E.coli O157:H7 86-24 within a microbial community was then monitored under various, yet ecologically relevant 
concentrations of nitrogen, as nitrate, and phosphorus, as a phosphate. Two reactors were constructed and therefore two experiments could be run simultaneously.

Table 2: Reactor amendments used in survivability study.

\begin{tabular}{|c|c|c|c|c|c|c|}
\hline \multirow{2}{*}{ Reactor amendments } & $\begin{array}{l}\text { pre- } \\
\text { Trial }\end{array}$ & $\begin{array}{l}\text { pre- } \\
\text { Trial }\end{array}$ & Trial 1 & Trial 2 & Trial 3 & Trial 4 \\
\hline & $\begin{array}{c}\text { No } \\
\text { E.coli }\end{array}$ & E.coli & E.coli & E.coli & E.coli & E.coli \\
\hline Unamended & $\mathrm{x}$ & $\mathrm{x}$ & $\mathrm{x}$ & & & \\
\hline 1ppm Peptone & & & $\mathrm{x}$ & & & \\
\hline $10 \mathrm{ppm} \mathrm{NO}$ & & & & $\mathrm{x}$ & & \\
\hline $100 \mathrm{ppm} \mathrm{NO}$ & & & & $\mathrm{x}$ & & $\mathrm{x}$ \\
\hline $0.2 \mathrm{ppm} \mathrm{PO}_{4}$ & & & & & $\mathrm{x}$ & \\
\hline $\begin{array}{c}10 \mathrm{ppm} \mathrm{NO} \mathrm{NO}_{3}+0.2 \mathrm{ppm} \\
\mathrm{PO}_{4}\end{array}$ & & & & & $\mathrm{x}$ & \\
\hline $\begin{array}{c}100 \mathrm{ppm} \mathrm{NO}_{3}+0.2 \mathrm{ppm} \\
\mathrm{PO}_{4}\end{array}$ & & & & & & $x$ \\
\hline
\end{tabular}

In development of the test system, three major components were considered: bulk fluid, inoculum, and the substratum. In an attempt to mimic the conditions that are found at the groundwater-well interface, well water was used as the bulk fluid. This was also 
used to provide a source of naturally-existing microbes that were present in a private, untreated well located in Ontario. Water was taken from this well, and also tested for its chemical properties using the general chemical tests available through PSC Environmental lab services. It was expected that the low nutrient content in the bulk fluid should create oligotrophic conditions, which in turn would discourage planktonic growth (White et al., 1999).

The inoculum will have an influence on biofilm formation. Several studies have shown that the order of inoculation will create different biofilm compositions (White $e t$ al., 1999). Since wells will have some level of biofouling once drilled, the annular reactors reflected this order. The biofilm was first given some time to develop with just the microbes naturally existing in the bulk fluid. The foreign microbe, E.coli O157:H7 86-24, was added after the initial biofilm development. The amount of time required for development can vary greatly, so the development time was determined experimentally. A thin layer of film was seen once the reactors were run for approximately two days. The slide was examined under a microscope, and it was observed that although most of the film visible to the eye was due to mineral deposits, bacteria were also present.

As mentioned, Camper, et al.'s work found that slowly-grown coliforms survived in their reactors at the highest concentrations (Camper et al., 1996). The lowest initial growth rate of $0.05 / \mathrm{h}$ enabled the coliforms to compete with the bacteria forming the initial biofilm. Since a pathogen in the environment would have been exposed to the stress of the environment (sunlight, loss of nutrient-rich environment) before reaching groundwater, it might be expected that the stress placed on the microbe during transport will aid in its ability to survive once it encounters a groundwater biofilm, because it is 
expected that its growth rate would be slow. E.coli $\mathrm{O} 157: \mathrm{H7} 86-24$ was grown for 24 hours to ensure bacterial growth was past a log phase of growth, and had entered its stationary phase. The cells, in this die-off phase, were used to aid in its ability to survive in the biofilm.

Substratum can have a dramatic effect on the biofilm formation, succession, and desquamation. Scheuerman et al., looked at substratum topography on bacterial adhesion. In their discussions with industry, it was believed that biofilms preferred to attach to rough surfaces. It was thought that perhaps this was due to higher surface area, protection from shear forces, and chemical changes that cause preferential physicochemical interactions. The Scheuerman study created grooves within a homogeneous silicon coupon 10,20,30, and 40 um deep. They unexpectedly found that the initial rates of attachment for the bacteria tested were independent of the grooves, where only motile organisms were found at the bottoms of the grooves. They did find that the initial rate of attachment was influenced by a higher fluid velocity, and concluded that attachment has a greater influence based on the transport from the bulk phase, onto the substratum (Scheuerman et al., 1998). Several other studies have also made a similar finding, where biofilm thickness is shown to increase with substrate loading, and not strongly affected by shear stress (Peyton, 1995, Soini. et al. 2002).

Camper, et al., operated annular reactors using oligotrophic conditions to look at the influence of growth conditions and substratum on long-term persistence of coliforms in mixed-population biofilms. They found that larger numbers occurred when mild steel was used instead of polycarbonate (Camper et al., 1996). This is an interesting finding since some wells have well screens that are made of stainless steel. In this lab study, 
glass slides were primarily used as the substratum due to its availability and ease of sample analysis. Stainless steel coupons were also used, but later abandoned. The annular reactors consistently had the greatest amount of growth near the water/air interface. This resulted in a concentrated strip of biofilm near the top of the slide. Depending on the conditions used, biofilm growth on the remainder of the slide varied greatly. The heterogeneity of the biofilm on the slide was an important observation, which could not be observed on the stainless steel coupons because the sample had to be disrupted to be viewed. Only a limited number of spaces were available in the reactors, so analysis was only performed using the glass slides.

\subsubsection{Annular reactor design \& conditions}

To study biofilms, laboratory and field reactors are commercially available. An annular reactor has an outer stationary cylinder with an inner rotating cylinder. The speed is set to mimic the liquid/surface shear of the water system in which the investigator is interested. The design of the reactor used in this study was loosely based on a paper by Lawrence et al., 2000 which compared the performance of a home-made and commercial reactor. Both systems compared similarly to each other with respect to biofilm development (Lawrence et al., 2000).

Annular Reactors were primarily designed and constructed as a cost-saving measure. Two reactors were built using $1.2 \mathrm{~L}$ translucent, polypropylene jars (Canadawide Scientific, 582-100-14). Two holes were drilled slightly smaller than the 
tubing (Masterflex 96400-16) to ensure a tight fit once the tubing was pushed through. The tubing was then sealed with a waterproof adhesive (Henkel 'Stik'n Seal'), and a plastic lid that was smaller than the jar was used as the slide holder. Eight wire clips were purchased ( $3 \mathrm{M})$ and attached symmetrically to the side of the smaller jar lid. The clips were attached using a combination of two-sided foam tape, and sealant. A hole was drilled in the center of the larger jar lid. and was fixed such that the jar lid could hold the slides. A $115 \mathrm{rpm}$ geared motor (Efton Science) was fixed using metal screws. The motor was run by attaching it to a $12 \mathrm{~V}$ power adapter. The speed of the inner cylinder was chosen based on the only motor available.
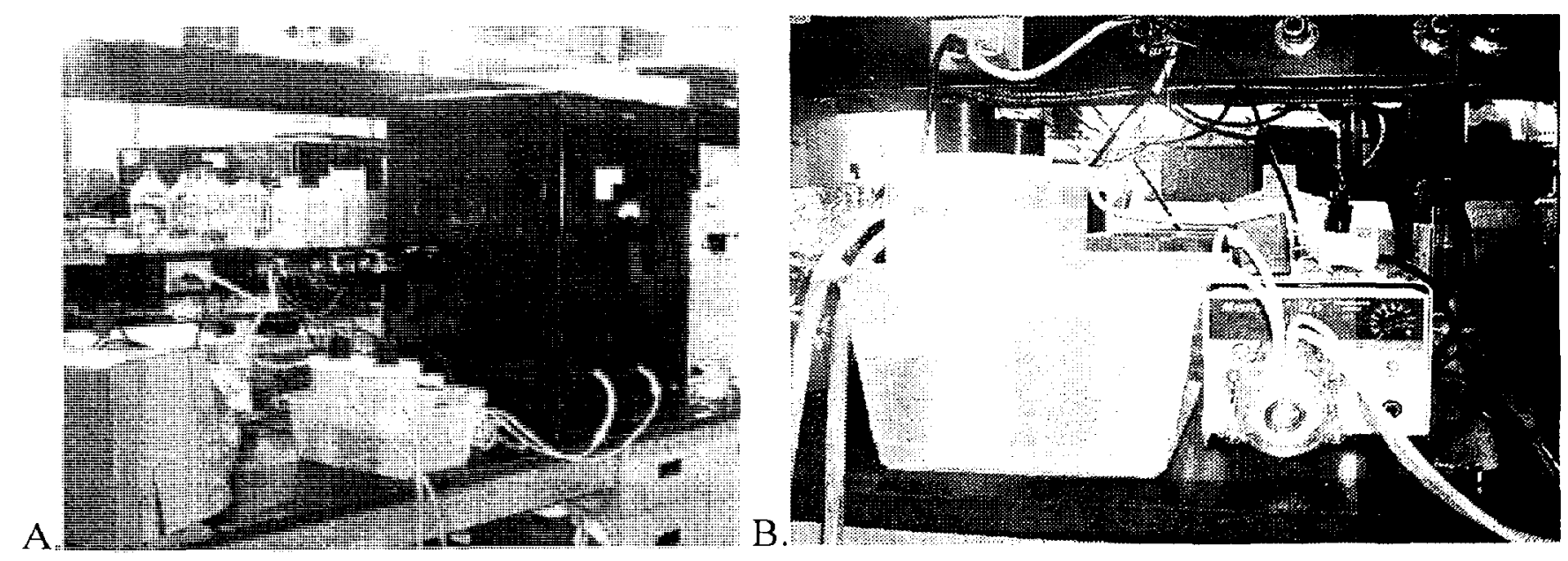

Figure 1: A. Full-view of the two reactors constructed, and used throughout the study. B. A closer view of the reactors attached to the pump. 
The two reactors were kept elevated in a plastic container to contain potential leaks. They were also covered by a cardboard box, to minimize light exposure.

Table 3: Physical Characteristics of the annular reactor

\begin{tabular}{|l|c|}
\hline Parameter & Reactor dimension $(\mathrm{cm})$ \\
\hline Diameter of slide holder & 8.6 \\
(inner jar lid) & 10.5 \\
\hline Diameter of slide holder + clip & 12.2 \\
holders & 13.2 \\
\hline Diameter of outer jar lid & $1 \mathrm{~L}$ \\
\hline Height of jar (with lid) & \\
\hline Working volume & \\
\hline
\end{tabular}

The home-made reactors had similar specifications to a BST (BioSurface Technologies Corporation) Biofilm Annular Reactor, used for biofilm growth and control studies using field-like conditions. More specifically, their reactor was designed to study biofouling, and treatment evaluation, where fluid shear and bulk fluid residence time are easily controlled. It is also suitable for pathogenic biofilms. This reactor can hold $1 \mathrm{~L}$ of fluid, and 20 slides. It is made of stainless steel, polycarbonate, or glass, and can run at a rotational speed of 20-288rpm (Websource: http://www.imt.net/ mitbst/reactors.html). 
The home-made reactor designed for this study was set up to receive well water that was stored in 20L carboys (Labcor. A-06082-50). and held at $4^{\circ} \mathrm{C}$. The water was pushed into the reactors using a peristaltic pump (Masterflex), at a flow rate of between $0.5-0.8 \mathrm{~mL} / \mathrm{min}$., or a dilution rate of $0.48 / \mathrm{hr}$. This was used since Camper et al., 1996 determined a dilution rate of $0.5 / \mathrm{h}$ to be most favorable to survivability of coliforms in a mixed-population biofilm (Camper et al.. 1996). After the first trial however, a timer was used to turn the pump off and on at 12 hour intervals. This was done to cut the amount of water used down substantially over the test period. The well-water was difficult to obtain, and was therefore used sparingly.

Before use, all components of the reactor were sterilized. A pre-trial run was performed to test the reactor. Both reactors were first sterilized by soaking them in bleach for two hours. The lid and clips were rinsed with $100 \%$ ethanol. Older tubes were used as the waste drainage tubes. These were scrubbed using a brush, and soaked in bleach. The entire reactor and tubes were then rinsed and flushed with milliQ water. The reactors were sterilized in this manner for each experiment. The carboys were initially cleaned using water and sodium bicarbonate just before water collection. The carboys were washed in between experiments using diluted bleach, followed by thorough rinsing with milliQ water. 


\subsubsection{Water Source}

Well water that was used in the experiment came from a well in Acton, from the Halton district. It was drilled using conventional rotary drilling on June 3,1981 . The well has since been used as the only water supply for a single household.

Table 4: General observations of well site.

\begin{tabular}{|l|l|l|}
\hline General Colour & Most Common Material & Depth (feet) \\
\hline Black & Top Soil & $0-2^{\prime}$ \\
\hline Brown & Overburden & $2-9^{\prime}$ \\
\hline Brown & Gravel-stones & $9-15^{\prime}$ \\
\hline White & Limestone & $15-38^{\prime}$ \\
\hline Grey & Rock-Limestone & $38-90^{\prime}$ \\
\hline
\end{tabular}

A five inch hole was drilled, and water was found at 78-90 feet. Steel casting was used for the first 26 feet. The remaining depth was left as an open hole. The pumping rate was determined to be eight gallons per minute, with a static level of nine feet. The water was clear at the end of pumping. This well was not treated before, or during use. The town of Acton also receives its municipal water from groundwater wells that are treated for removal of naturally occurring iron and manganese. Ultraviolet radiation and chlorine is used to make the water safe for consumption (The New Tanner, 2004). 
The following table shows the chemical composition of the water used in this experiment. Water was collected on two separate occasions for use throughout the experiments. The sample used for chemical testing occurred on the first collection date. The concentrations are also compared to concentrations of chemicals obtained from published results of Walkerton water shortly after the E.coli O157:H7 outbreak. Although the outbreak was largely due to the lack of chlorination of water, it is also true that E.coli $\mathrm{O} 157: \mathrm{H} 7$ was able to persist in the subsurface long enough to cause disease. It is therefore useful for this study, which is performed using subtle nutrient differences, to look at the concentrations of various nutrients present at the time of this recent outbreak. 
Table 5: Concentrations of various chemicals found in the bulk fluid

\begin{tabular}{|c|c|c|c|}
\hline Test & $\begin{array}{l}\text { Acton } \\
(\mathrm{ppm})\end{array}$ & $\begin{array}{l}\text { Walkerton } \\
\text { (ppm) }\end{array}$ & $\begin{array}{l}\text { ODWS parameter } \\
(\mathrm{ppm})\end{array}$ \\
\hline $\mathrm{Ca}$ & 71.3 & & \\
\hline $\mathrm{Cr}$ & $<0.005$ & & 1 \\
\hline $\mathrm{Cu}$ & 0.0008 & 0.0011 & 1 \\
\hline$\overline{\mathrm{Fe}}$ & 0.57 & 0.009 & 0.3 \\
\hline $\bar{K}$ & 0.7 & & $<2000$ \\
\hline $\mathrm{Mg}$ & 22.4 & & $<50$ \\
\hline$\overline{M n}$ & 0.007 & & 0.05 \\
\hline $\mathrm{Na}$ & 3 & 5.8 & 200 \\
\hline $\mathrm{Zn}$ & 0.008 & & 5 \\
\hline $\mathrm{F}^{-}$ & 0.1 & 0.68 & 1.5 \\
\hline $\mathrm{Cl}^{-}$ & 4.2 & & $<250$ \\
\hline $\mathrm{NO}_{2}-\mathrm{N}$ & $<0.2$ & & $10($ N-combined $)$ \\
\hline $\mathrm{NO}_{3}-\mathrm{N}$ & $<0.2$ & 1.53 ave. & $10(\mathrm{~N}$-combined $)$ \\
\hline$\overline{\mathrm{SO}_{4}}$ & 47.4 & & 500 \\
\hline $\mathrm{PO}_{4}^{3-}$ & $<1$ & & 0.2 \\
\hline $\mathrm{NH}_{3}-\mathrm{N}$ & 0.03 & & 0.5 \\
\hline$\overline{\mathrm{DOC}}$ & 0.6 & & $<1$ \\
\hline $\mathrm{CO}_{3}$ & 1 & & \\
\hline $\mathrm{HCO}_{3}{ }^{-}$ & 283 & & \\
\hline $\mathrm{pH}$ & 7.92 & & \\
\hline Hard(Calc) & 270.3 & 386 & $80-100$ \\
\hline
\end{tabular}




\subsubsection{GFP-labeled E.coli O157:H7 86-24}

E.coli O157:H7 86-24 was used as the foreign microbe. It was used because it has the green fluorescent protein (GFP) marker incorporated into its chromosome. GFP was originally isolated from Coelenterates (e.g. jellyfish), and can be expressed in both prokaryote and eukaryote systems. When GFP is exposed to blue light, it fluoresces green. It will fluoresce within hours of its production, making it an excellent reporter. (So et al. 2002, Bilge et al., 1996).

E. coli $\mathrm{O} 157: \mathrm{H} 7$ T86-24 was obtained using E. coli JB122, carrying a GFP vector (pJBA29), which was provided by J.T. Trevors from the University of Guelph. This vector was then transformed into Escherichia coli $\mathrm{O} 157: \mathrm{H7}$ 86-24 (wild-type), provided by P. Tarr (So, et al., 2002), where the GFP gene then became integrated into genomic DNA. This transformation experiment, creating Escherichia coli O157:H7 T86-24, was performed by Mitsuko Kanetani at Ryerson University.

\subsubsection{Experiment overview}

Once the reactors were designed, a month was spent testing to make sure they were operational. The well water was brought from Acton, Ontario by car and stored at $4^{\circ} \mathrm{C}$. To minimize use of the water, the flow rate was kept to a minimum. The lowest achievable flow rate for the pumps that were available was $0.5 \mathrm{~mL} / \mathrm{min}$. During the initial testing, the pumps would at times stop all together, so the pump was run at 0.5 - 
$0.8 \mathrm{~mL} / \mathrm{min}$. to minimize this problem. Timers were used to have the pump turn off and on every 12 hours. This was considered acceptable for the experiment because private well pumps are not constantly running. Since biofilm was developing at these low flow rates, and in unamended conditions, it was considered acceptable conditions to run the experiments. This enabled a reactor experiment to be performed in four weeks, using approximately $10 \mathrm{~L}$ for each reactor.

Four experiments were run (Table 6). The first took place for a duration of 25 days. Reactor 1 was amended with a final concentration of $1 \mathrm{ppm}$ peptone, as was done in the Banning et al. study. Ten days were given for the biofilm in the reactors to develop. GFP-E.coli was grown for 24 hours in LB broth, spun and washed twice in TBS buffer. The cells were split between two microcentrifuge tubes, and the wet weight was recorded. The cells were then resuspended into well water taken from the reactors. Each reactor was then seeded with the E.coli $86-24-G F P$ and left to run as a batch reactor for 24 hours. The addition of E.coli 86-24-GFP was considered Day 1 for each experiment. Twenty-four hours after E.coli $86-24-G F P$ was added, the pump was run continuously at $0.5-0.8 \mathrm{~mL} / \mathrm{min}$. The pump was also turned off when slides were being removed and replaced from the reactors. Trials 2-4 were performed in a similar manner, except with the addition of the timer allowing for 12 hours off and on with the pumps. The following table summarizes the experiments run, and the duration of each. Pre-E.coli indicates how many days the reactors were run before adding E.coli 86-24-GFP, and Post-E.coli indicates how many days the reactors ran after E.coli 86-24-GFP was added. 
Table 6: Experiment overview

\begin{tabular}{|c|c|c|c|c|c|}
\hline Trial & Reactor & Conditions & Pre-E.coli & Post-E.coli & Total \\
\hline \multirow{2}{*}{1} & 2 & Unamended & 10days & 16 days & 26days \\
\hline & 1 & Peptone $1 \mathrm{ppm}$ & 10days & 16 days & 26days \\
\hline \multirow{2}{*}{2} & 2 & $10 \mathrm{ppm} \mathrm{NO}$ & 3 days & 19days & 22days \\
\hline & 1 & $100 \mathrm{ppm} \mathrm{NO}$ & 3 days & 19days & 22 days \\
\hline \multirow[b]{2}{*}{3} & 2 & $0.2 \mathrm{ppm} \mathrm{PO}_{4}$ & 3 days & 12days & 15 days \\
\hline & 1 & $\begin{array}{l}0.2 \mathrm{ppm} \mathrm{PO}_{4}+ \\
10 \mathrm{ppm} \mathrm{NO}\end{array}$ & 3 days & 12days & 15 days \\
\hline \multirow[b]{2}{*}{4} & 2 & $\mathrm{NO}_{3} 100 \mathrm{ppm}$ & 4days & 16days & 20days \\
\hline & 1 & 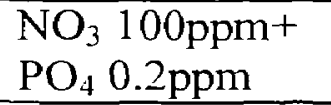 & 4 days & 16days & 20days \\
\hline
\end{tabular}

\subsection{Microscopy Tools}

Light microscopes can visualize structures that are in the scale of a few micrometers. The biggest advantage using light microscopes is that one can visualize a specimen under natural conditions. The resolution limit is $0.16 \mathrm{uM}$ in theory, but $0.3 \mathrm{uM}$ in practice. Many tools now exist to aid in microbial studies that use microscopy to analyze results. For example, various components of biofilms can be visualized using a variety of stains. Negative staining aides the detection and determination of EPS (Hoppert, 2003). Nucleotide structure can be visualized by DAPI (4',6-diamidino-2phenylindole) staining. This requires chemical fixation, therefore artificial alterations may occur. When thick specimens need to be monitored. confocal microscopy is the superior tool, although standard bright-field and fluorescence microscopes can still be used. Biofilm may be embedded in an appropriate matrix (gelatin, paraffin, resins), and 
sliced to visualize a vertical axis to the surface. Stains with an affinity for exopolysaccharides will highlight the EPS. Other common techniques involve staining of cellular DNA (ethidium bromide, fluorescein), cells (propidium iodide), and EPS (calcofluor), that are visualized by using the appropriate filters (Hoppert, 2003, Davey and O'Toole, 2000). Confocal laser scanning microscopy has been successfully used for routine analysis of biofilms. Although it is an extremely powerful tool, one drawback is difficulty in quantifying results. Accuracy may also require the determination of bias that can be due to the experimenter's preferences (Webb et al., 2003).

\subsubsection{Experiment overview using microscopy}

GFP expression was monitored using a confocal scanning laser (Zeiss LSM 510), and epifluorescence microscopy (Zeiss HAL). The later was used more extensively, as it provided a simpler means of comparing GFP cells with the naturally occurring microbes. Since most of the trials produced fairly thin biofilms, observations with the epifluorescence microscope were clear.

When sampling, the pumps were stopped, and the reactor was opened. A slide was then removed (in most trials, they were not replaced), and transferred to a container. One side of the slide was then scraped using a razor (always the side that was facing inwards), and gently rinsed with TBS (Tris buffered saline) buffer. This was then transferred with a transfer pipette, to a microcentrifuge tube and immediately stored at $20^{\circ} \mathrm{C}$. These samples were later used to extract genomic DNA for analysis by PCR. 


\subsection{Molecular Tools}

Understanding the composition and physiology of microbial communities has been greatly enhanced by the use of techniques in molecular biology. Methods are typically based on detection and analysis of nucleic acids, proteins, and lipids. Analysis of DNA in particular is largely based on using polymerase chain reaction (PCR), combined with a means of visualization to interpret the results (Rochelle, 2001).

\subsubsection{DNA isolation}

Biofilms developed throughout the experiment were collected, and stored at $-20^{\circ} \mathrm{C}$. Genomic DNA was then isolated on two separate occasions, using two separate kits. MOBIO's UltraClean kit was first used, following the manufacturer's procedure. A second kit, Qiagen's DNeasy Tissue kit, was used on majority of the samples due to its simpler procedure. This kit can isolate genomic DNA from both gram-positive and gram-negative bacteria. The protocol for purifying genomic DNA from gram-positive bacteria was used, because it would ensure that both gram-positive and gram-negative bacteria would be lysed. 


\subsubsection{PCR using O157-specific primers}

The various genetic factors which contribute to E.coli $\mathrm{O} 157: \mathrm{H} 7$ 's virulence are found on phage, plasmid and chromosomal genes (Law, 2000). E.coli strains expressing lipopolysaccharide O-antigen, contain the $\mathrm{rfb}$ gene cluster. This cluster is made of 12 genes, including the fifth gene rfbE, which is specific to E.coli O157:H7. Detection of O157 by polymerase chain reaction (PCR), which amplifies part of rfbE, was developed for food-PCR diagnostics. Abdulmawjood et al. developed primers that have been tested on 155 strains of $\mathrm{O} 157$ from a wide variety of sources. Internal amplification controls were developed to prevent false negative results, but these were not used in this study (Abdulmawjood et al., $2002 \& 2003$ ).

PCR primers were used as designed by Abdulmawjood et al.: Gi-O157-I 5 '-CGA GTA CAT TGG CAT CGT G-3', Gi-O157-II 5'-ATT CGC CTG AAG CCT TTG-3'. The PCR reaction (25uL) contained $0.75 \mathrm{uL}$ of each primer $(10 \mathrm{pmol} / \mathrm{uL}), 2.5 \mathrm{ul}$ dNTP (10mmol), 2.5uL of PCR buffer, 2.5uL of $25 \mathrm{mM} \mathrm{MgSO}_{4}$, and $0.25 \mathrm{uL}$ optimase (Transgenomic), $13.75 \mathrm{uL}$ sterile milliQ water, and $2 \mathrm{uL}$ of genomic DNA. This reaction was performed using an MJ Thermocycler. The following program was used: $1 \times 5 \mathrm{~min}$. precycle at $95^{\circ} \mathrm{C}, 30 \times 30 \mathrm{~s}$ at $95^{\circ} \mathrm{C}, 40 \mathrm{~s}$ at $55^{\circ} \mathrm{C}, 45 \mathrm{~s}$ at $72^{\circ} \mathrm{C}$, and a final extension of $72^{\circ} \mathrm{C}$ for $5 \mathrm{~min}$. The PCR conditions were altered from the original paper to optimize them for use with DHPLC, and therefore using optimase as the enzyme. 


\subsubsection{PCR using 16S rRNA primers}

It is very common to use $16 \mathrm{~S}$ rRNA genes in deciphering microbial diversity. These genes control protein translation, and are therefore conserved within various taxonomic groups. Using 16SrRNA DNA is not without difficulties. but offers great promise in detecting new species. A study done by Rivas et al, attempted to identify microorganisms with universal primers containing sequence present in both Prokaryotes and Eukaryotes: 16S rRNA in Prokaryotes. and 18S rRNA in Eukaryotes. The paper described two areas where highly conserved sequences in all organisms would allow amplification for both prokaryotes (495bp). and eukaryotes ( $508 \mathrm{bp}$ ). The area was named the universal amplified ribosomal region (UARR), located in the V6. V7, and V8 domains from rRNA (Rivas, et al., 2004), or position 909-1404 E.coli, and position 1134 1642 in $S$. cerevisiae. To reduce the specificity of the primers, and therefore increase the likelihood of amplifying more DNA from the various microbes present, degenerate primers were used. These are primers that are designed such that certain sites will incorporate a variety of bases, instead of specifically just one. This is also sometimes referred to as a wobble.

New taxa with $16 \mathrm{~S}$ rRNA sequences are revealing that some sequences are not universal to some $16 \mathrm{~S}$ rRNA primers previously used. As a result it is likely that current $16 \mathrm{~S}$ libraries do not truly represent prokaryotic diversity. Baker et al., 2003, reassessed commonly used $16 \mathrm{~S}$ rRNA primers and subsequently designed two new pairs for Archaeal amplification. For amplification of Prokaryotes, they recommended Watanabe et al.'s 16S rRNA primers. These primers give a 195 bp product, and in the $\mathrm{V} 3$ region 
(Wantanabe et al., 2001, Baker et al., 2003). In their sequence analysis, Baker et al. found the longest string of completely conserved sequence is at E.coli position 788-798 (Accession\# X80724). The rest are found in strings of less than four bases. This clearly shows that no primer can be a $100 \%$ match for all bacterial. The universal primer design is a compromise between trying to get universal complimentary sequence and all other aspects of primer design (primer-dimer formation, annealing temperature, $\mathrm{G} / \mathrm{C}$ ratio). Poor complimentarity (especially at the $3{ }^{\prime}$ end) can lead to under representation of certain genotypes. To solve this, degenerate nucleotides have been used to gain 'universal specificity'. These primers however can have a biased template-to-product ratio. Too much degeneracy can lead to amplification of non-target genes. Inosine was used in this study. They allowed no more than $25 \%$ total degeneracy and less than $10 \%$ inosine residues per primer to minimize bias introduced by this type of primer design. Bias is seen with different priming efficiencies causing differential amplification, interference by flanking primer regions, and different kinetics in the PCR reaction itself. No primer is truly universal, so the goal is to try to find an acceptable amount of bias (Baker et al., 2003).

An interesting approach to $16 \mathrm{~S}$ rRNA analysis is the use of nested primers. Boon et al., 2002 used this approach where they first performed PCR on broad bacterial groups. They looked at Bacteria, and alpha-proteobacteria, as well as for Actinomycetes, ammonium oxidizers, and methanotrophs. This was followed by a second PCR reaction using bacterial primers (P338F, P518R) (Boon et al., 2002). It must be noted that two successive PCRs can introduce an even greater bias if preferential amplification occurred. A nested approach, for WWTP aimed to standardize DGGE for group-specific 16S rRNA 
PCR fragments. The first round had seven sets of primers for different microbial groups.

A second set was used for 'Bacteria', to reduce and equalize the length of the specific primers and to add a GC-clamp. This better revealed subtle changes within or differences between microbial communities (Boon et al., 2000).

Since there are so many publications that use $16 \mathrm{~S}$ primers for analysis, an extensive review of literature on their use was not done. A strong attempt was made to find primers that were carefully designed in the past that could be successfully used in this study.

Table 7: Primers used for $16 \mathrm{~S}$ rRNA PCR analysis.

\begin{tabular}{|c|c|c|c|c|c|}
\hline & 16S Primers & Sequence & Size & Region & Reference \\
\hline \multirow{2}{*}{$\begin{array}{l}\text { Set } \\
1\end{array}$} & $933 \mathrm{~F}$ & gcacaagcggtggagcatgtgg & \multirow{2}{*}{$474 b p$} & \multirow{2}{*}{ V6,V7,V8 } & \multirow{2}{*}{$\begin{array}{l}\text { Transgenomic } \\
\text { Domman et al., } \\
2001\end{array}$} \\
\hline & $1407 \mathrm{R}$ & gacgggcggtgtgtacaag & & & \\
\hline \multirow[t]{2}{*}{ Set } & $338 \mathrm{~F}^{*}$ & cgteccgecgececcgectcctacgggaggcagcag & \multirow{2}{*}{$181 \mathrm{bp}$} & \multirow{2}{*}{ V3 } & \multirow{2}{*}{ Transgenomic } \\
\hline & $519 \mathrm{R}$ & ggtattaccgcggcggctg & & & \\
\hline \multirow{2}{*}{$\begin{array}{l}\text { Set } \\
3\end{array}$} & $\mathrm{I}-341 \mathrm{fGC} \mathrm{C}^{* *}$ & cctacgggiggcigca & \multirow{2}{*}{$192 \mathrm{bp}$} & \multirow{2}{*}{ V3 } & \multirow{2}{*}{ Baker et al., 2003} \\
\hline & $\mathrm{I}-533 \mathrm{r}$ & tiaccgiiictictggcac & & & \\
\hline \multirow{2}{*}{$\begin{array}{l}\text { Set } \\
4\end{array}$} & A571F & gcytaaagsriccgtagc & \multirow{2}{*}{$633 b p$} & \multirow{2}{*}{ V4-V7 } & \multirow{2}{*}{ Baker et al., 2003} \\
\hline & VAI204R & ttmggggcatrcikacct & & & \\
\hline
\end{tabular}

*20 bp GC clamp cgecegecgegecccgegcc

**40 bp GC clamp cgccegccgegegeggcgggcggggcgggggcacgggggg 


\subsubsection{Denaturing High Performance Liquid Chromatography (DHPLC)}

DHPLC or temperature-modified heteroduplex analysis (TMHA), development began 10 years ago when alkylated nonporous poly(styrene-divinlybenzene) particles of 2 um were developed. This was used as a stationary phase, and alkylammonium ions used in liquid phase to allow for size dependent chromatographic DNA separation. It was then discovered that heteroduplexes (DNA with a mismatch due to the presence of DNA sequence variation), and homoduplexes (DNA without a mismatch in the sequence), in partially denaturing conditions would have slightly different retention times on the column. The retention time is reduced for the heteroduplexes because the bridging molecule, triethylammonium acetate (TEAA), is not attracted as strongly to mismatched DNA. It is therefore not retained on the column as long as the homoduplex DNA fragments, when acetylnitrile is increased to compete with the TEAA. As a result, single nucleotide substitutions, deletions, and insertions can be detected in a 200-1000 bp PCR product, with sensitivity and specificity approaching $100 \%$. (Premstaller \& Oefner, 2003).

One of the first publications to describe the use of DHPLC in an attempt to identify bacteria was by Hurtle et al. using universal primers. The results showed that they were able to distinguish 36 of the 39 bacteria examined which were identified by unique peak shapes (Hurtle et al., 2002) A variety of other studies have been published using DHPLC in microbiology applications. Some examples are mutation detection in quinolone-resistant Salmonella enterica, and Staphylococcus aureus (Hannachi-M'Zali et al., 2002), polymorphisms in Mycobacterium tuberculosis (Cooksey et al., 2002), and 
genotyping bacteria by MLST-DHPLC (multilocus sequence typing) (Shlush et al., 2002). Another study looked at fingerprinting bacteria in groundwater and mineral water used (Dewettinck et al., 2001). This paper proposed the use of PCR-DGGE as a rapid way to examine the bacterial quality of waters. This might be superior over existing methods because the relationship between indicator organisms and pathogens has been questioned. Commonly used plating methods require long incubation periods. The proposed technique required resusitation was used by adding $1 \mathrm{~g} / \mathrm{L}$ of peptone to some samples. The different water types examined were found to have different DNA fingerprints.

Another study, by Domman et al., used 16S rRNA primers to identify bacteria in the urinary tract of renal transplant recipients. A $100 \%$ correlation was found to that of culture-positive specimens, and in some cases culture-negative cases, could be detected using DHPLC. DHPLC has also been used to identify sequence variation in Mycobacterium tuberculosis. (Cooksey et al., 2002), by looking at the products of five genes where mutations have been associated with drug resistance. All twenty expected polymorphisms were detected. (Domann et al., 2003).

While DGGE and DHPLC measure similar melting characteristics, DHPLC may become more robust for detection and purification of DNA with sequence variations. (Skopek et al., 1999) although few, if any, studies have been performed that compare the two at the same time. 


\subsubsection{Experimental design using PCR and DHPLC}

All PCR products were analyzed using DHPLC. The 0157 primers were examined in non-denaturing conditions $\left(50^{\circ} \mathrm{C}\right)$, to look for the presence or absence of the $500 \mathrm{bp}$ product. The conditions given in the paper did not produce any PCR product, so the reactions were re-optimized (see Section 4.3.2). Transgenomic's size ladder was used to determine the retention time of $500 \mathrm{bp}$.

Three primers were chosen for $16 \mathrm{~S}$ rRNA analysis based on previous publications (Table 7), but ultimately only one set provided a PCR product of the correct size. The other primer sets did not produce any product, despite many attempts.

Set 2 (Table 7) was used with the following PCR recipe: premix (dNTP, buffer, water) $21.25 \mathrm{uL}, 0.5 \mathrm{uL}$ forward primer, $0.5 \mathrm{uL}$ reverse primer, $0.25 \mathrm{uL}$ Amplitaq gold (Qiagen), 2.5uL DNA (final volume of 25uL). Touchdown PCR was done with an initial denaturing of $95^{\circ} \mathrm{C}$ for 10 minutes, followed by 14 cycles (with a $0.5^{\circ} \mathrm{C}$ decrease in annealing temperature per cycle) of $95^{\circ} \mathrm{C}$ for 30 seconds, $58^{\circ} \mathrm{C}$ for 40 seconds, and $72^{\circ} \mathrm{C}$ for 45 seconds. The remainder of the PCR was 19 cycles of $95^{\circ} \mathrm{C}$ for 30 seconds, $51^{\circ} \mathrm{C}$ for 40 seconds, and $72^{\circ} \mathrm{C}$ for 45 seconds, with a final extension of $72^{\circ} \mathrm{C}$ for 5 minutes. Analysis was done using DHPLC, in both denaturing and non-denaturing conditions.

The optimal temperature was predicted using Transgenomic's Navigator software. Several melting profile calculations and temperature predictions are incorporated into an algorithm based on the 'Fixman-Freire modification of the Poland method'. Several temperatures were used experimentally, and a final temperature is chosen based on these results. 


\section{Results}

1. The use of constructed annular reactors to study biofilms.

Two annular reactors were run simultaneously during this study. The reactors were subject to four one-month trials, resulting in a total of eight separate experiments. In each experiment, a naturally-occurring biofilm was given 2-3 days to develop before the single addition of the foreign microbe occurred. After the first day of running the reactors, a small film could be seen on the slides. Crystals, likely minerals from the water, were quick to attach to the glass slide and within days microbes could be seen forming a biofilm. With respect to overall biofilm appearance, all eight experiments produced similar biofilms. The slide had biofilm growth similar to what has been described in previous papers. There were areas of patchy growth, and areas of open space especially towards the bottom of the slide. This might have been the result of less available oxygen towards the bottom of the reactor. Since minerals were observed as the first object that attached to the slides, it is possible that the naturally-occurring microbes introduced to the slides may have traveled there because they were initially attached to these minerals. They then became attached to the slide with them, and once on a larger surface, were able to colonize the slides. A concentrated strip of biofilm always occurred near the top of the glass slide, at the air-water interface. This was the area where the thickest biofilm developed. 

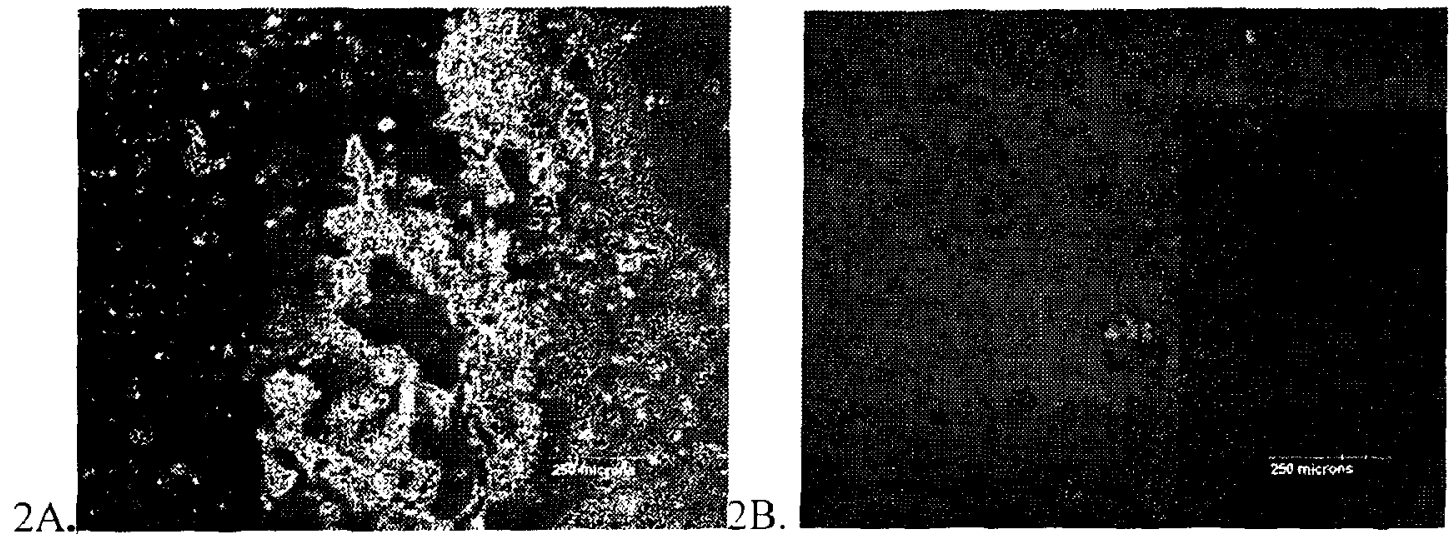

Figure 2: Biofilm strip typically found in the water/air interface of the slide.

A. Image from inverted microscope, taken from a 7-day old biofilm, amended with $100 \mathrm{ppm} \mathrm{NO}_{3}$. B. Image from inverted microscope, taken from an 8-day old unamended biofilm.

In Figure $3 \mathrm{~A}$, microbes are shown attached and accumulating on the slides without the addition of any amendments. Figure $3 \mathrm{~B}$ demonstrates that in the highest nutrient conditions used, $1 \mathrm{ppm}$ peptone, biofilm growth is considerably greater, and with fewer open spaces. Filamentous bacteria are also observed. 

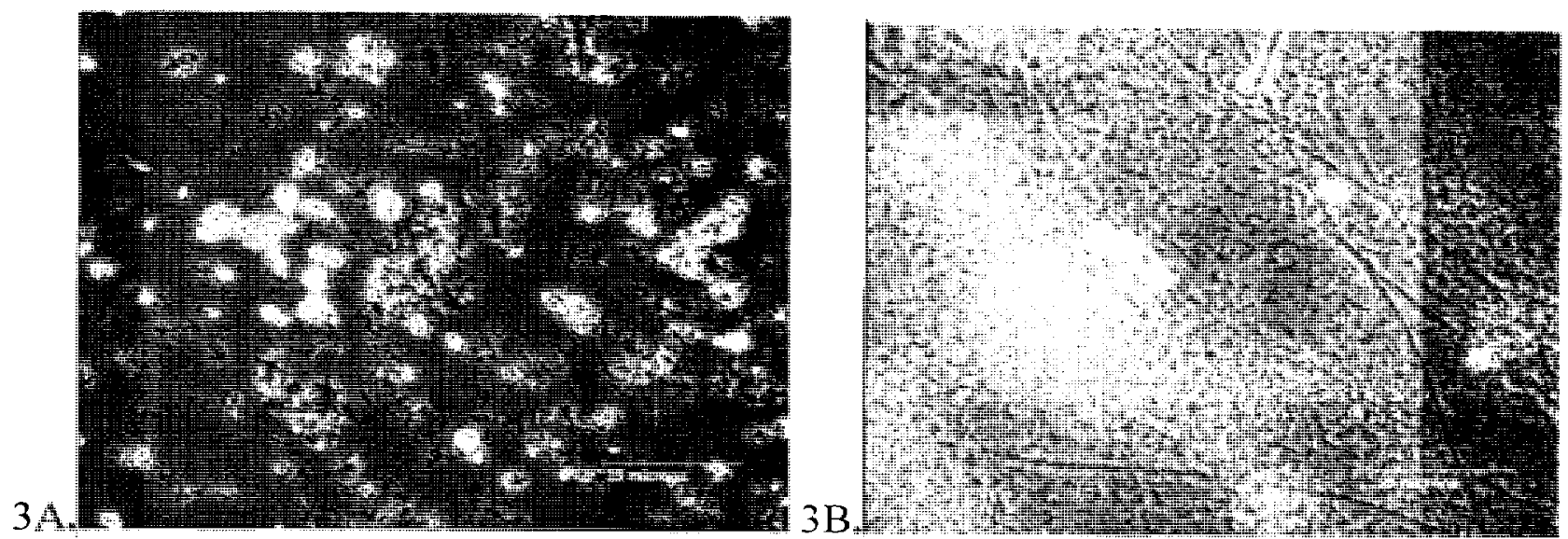

Figure 3: A. Unamended biofilm given 11 days to develop. B. Reactor amended with 1 ppm peptone. Both images were taken one day after E.coli 86-24-GFP was added.

At the end of the first experiment, gram staining was performed on the final slide of the reactor amended with $1 \mathrm{ppm}$ peptone. The staining revealed that the biofilm was dominated by gram negative cocci seen in clusters, chains and pairs. Areas containing gram negative microbes are also seen but the shape of their shape is not clear. Gram negative, filamentous bacteria stretch out from the clusters. Some gram negative, rodshaped bacteria can also be seen (Figure 4). 

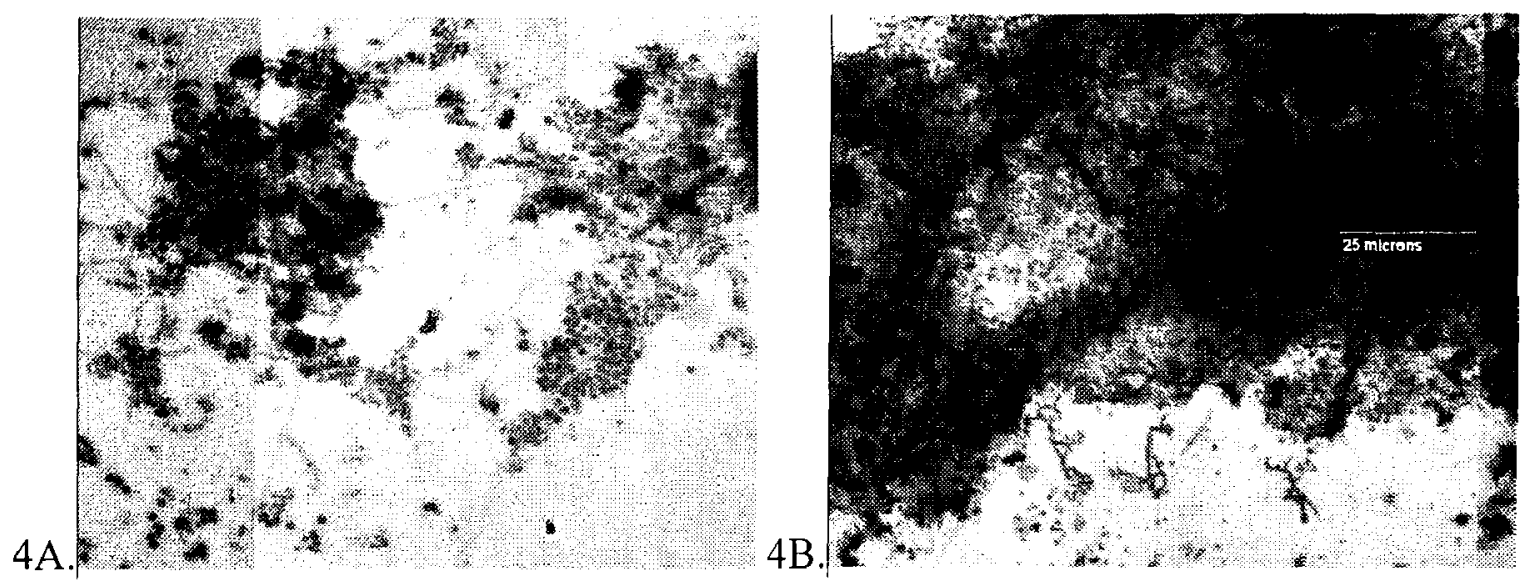

Figure 4: A, B. Gram stains of slide, 26 days from the start of experiment, $1 \mathrm{ppm}$ peptone. Images show various microbes: cocci, filamentous, and rod-shaped bacteria. 


\section{Integration of a foreign microbe}

Escherichia coli $\mathrm{O} 157: \mathrm{H} 7 \mathrm{~T} 86-24$ was grown in LB broth to a stationary phase of growth, and used to seed the annular reactors. The reactors were then monitored closely to observe its ability to integrate into the established biofilm. An average wet weight of $0.0265 \mathrm{~g}$ was added to each reactor. A pellet wet weight of $3 \mathrm{~g}$ is approximately equal to 3-4 $\times 10^{9}$ cells (Qiagen benchguide, 2005). Therefore, a single addition of approximately $3 \times 10^{7}$ cells was added for each experiment. Once the foreign microbe was added. sampling occurred every few days. A total of ten sampling slides were available in each experiment to monitor foreign microbe integration and persistence. The large amount of E.coli 86-24-GFP added did not accurately reflect the amount of bacterial cells that might be expected to enter groundwater in a natural environment. Analysis of the waste stream showed that after the 24-hour batch period, E.coli $86-24-$ GFP washed out of the reactors. It is likely that less E.coli $86-24-G F P$ could have been added to achieve biofilm integration. Despite this large addition. the fluid in the reactors always remained clear. This suggested that at no time did planktonic growth occur for E.coli 86-24-GFP. This was observed in every reactor condition used. Strong evidence of an inability for E.coli 86-24-GFP to grow planktonically, was demonstrated when replacement slides were added to the first experiment. GFP-labeled E.coli 86-24-GFP was only added at the beginning of the experiment, and was never found to colonize any replacement slides added after its initial addition.

Once E.coli $86-24-G F P$ was added to the reactor, it integrated itself into the existing biofilm. It was generally able to integrate throughout, and survive for up to two 
weeks. Immediately after its addition, large numbers were seen to colonize the biofilm. Over time, fewer cells expressed the green fluorescent protein. Since its persistence could only be monitored by the presence of GFP, persistence beyond the use of this marker could not be established. It is possible that in the nutrient-limiting conditions, the cells may have become less active and therefore ceased to express GFP. This would be the case for cells becoming quiescent, as a mechanism for survival.

Figure $5 \mathrm{~A}$ and $5 \mathrm{~B}$ were taken at the same location, but $5 \mathrm{~A}$ was taken using regular light, and 5B under UV light. These images demonstrate the ability of E.coli 86-24-GFP to successfully integrate into the naturally-occurring biofilm. Here they are located near other microbes. and often near the mineral deposits.
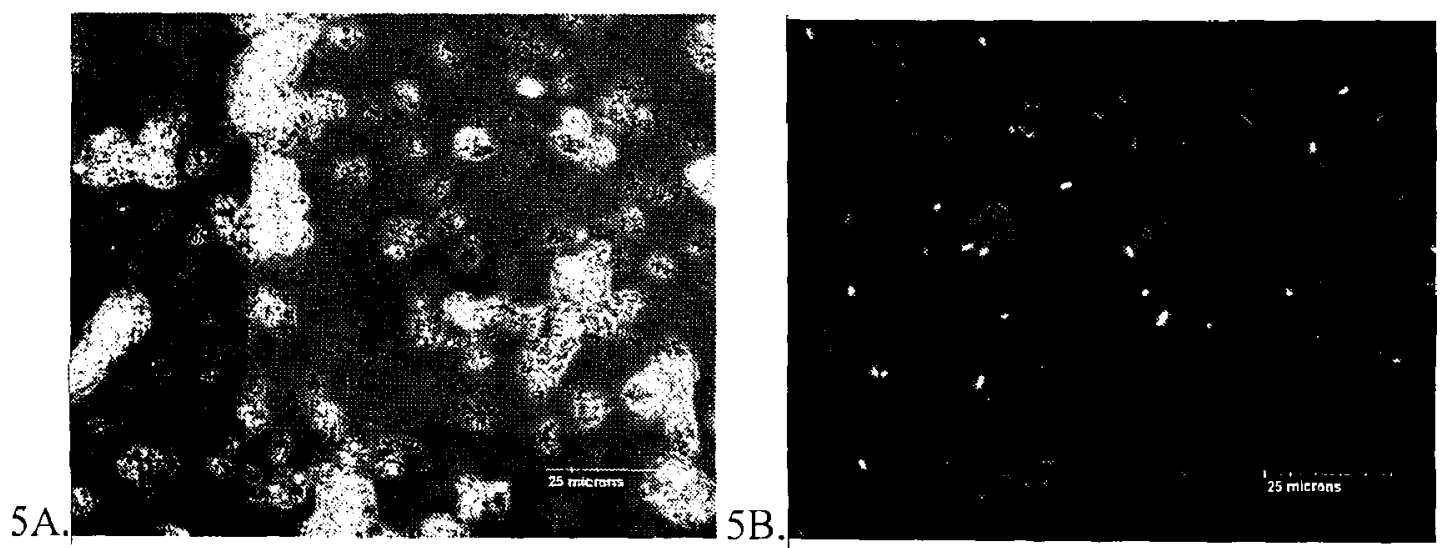

Figure 5: A. Unamended reactor, 7 days after E.coli 86-24-GFP was added.

B. Unamended reactor, 7 days after E.coli 86-24-GFP was added, UV light. 
3. Nutrient effects on E.coli 86-24-GFP persistence

It was found that when more nutrients were added, a greater amount of biofilm was observed. Biofilm growth of the natural microbes was greater, when $1 \mathrm{ppm}$ of

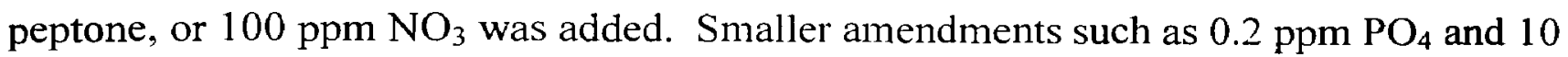
ppm $\mathrm{NO}_{3}$ looked similar to the unamended biofilm. It should be noted that the chemical test results of the well water reported that there was less than $1 \mathrm{ppm}$ of $\mathrm{PO}_{4}$, and therefore the actual concentration was not known. The highest amount of nutrients used was 1 ppm of peptone added to the bulk fluid. This 'high-nutrient' experiment did not show evidence of planktonic growth, but did develop the thickest biofilm when compared to all other experiments. The naturally-occurring microbes also appear smaller than the E.coli 86-24-GFP cells (Figure 5). The following figures are representative images that provide a pictorial summary of the eight experiments performed in this study. All photos were taken using epifluorescence microscopy. 

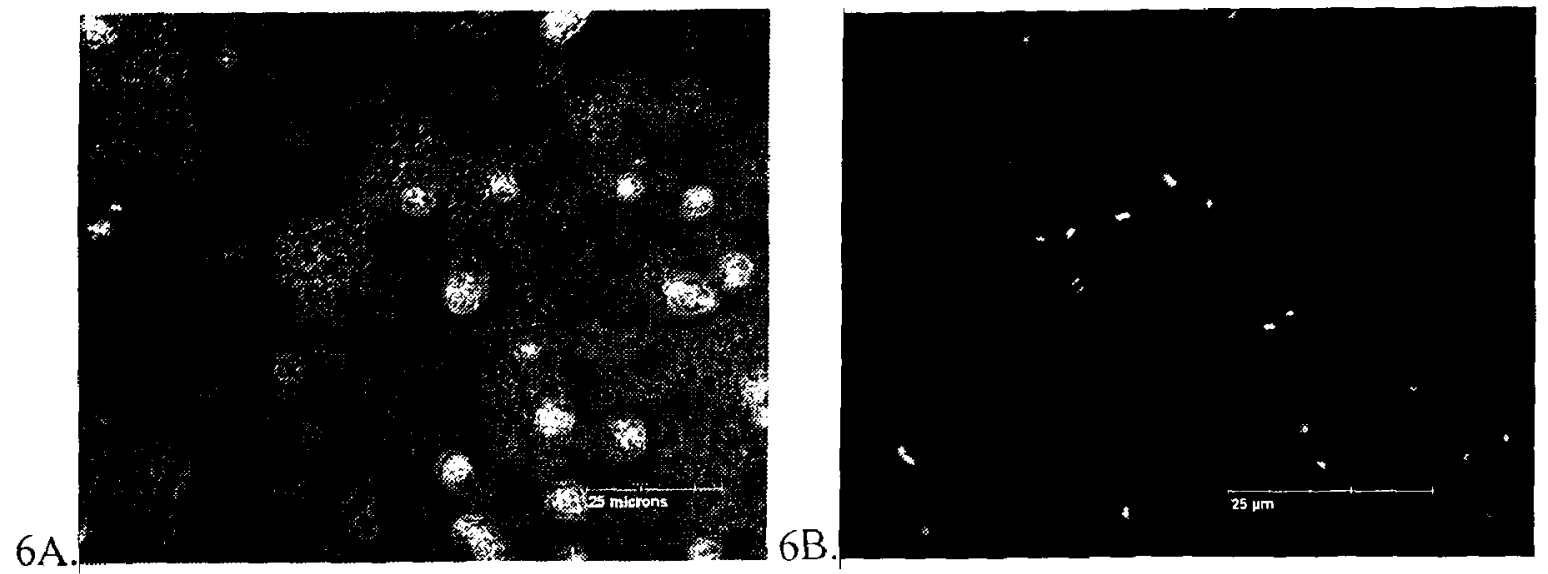

Figure 6: Amended I ppm peptone, 7 days after E.coli 86-24-GFP was added.
A. Image near top, under regular light. B.
B. Same image as $\mathrm{B}$, but under UV light.

Slides from the reactor amended with $1 \mathrm{ppm}$ of peptone had more biofilm development overall, but after one week, the amount of GFP seen is similar to the unamended reactor (Fig.5). The naturally-occurring biofilm does appear to take a greater advantage of the increased nutrients than the foreign microbe. E.coli $86-24-\mathrm{GFP}$ was only added once, whereas the naturally-occurring microbes existed in the bulk fluid, and was therefore constantly being added. The single dose of E.coli $86-24-G F P$ was used to reflect a single transportation event (e.g. transport into groundwater due to a heavy rainstorm). The success of the other microbes might have simply covered the E.coli $86-$ 24-GFP decreasing its access to the outer layers where oxygen and nutrients would be more readily available.

The next series of images (Figures 7-9) compare the detection of GFP in 10ppm $\mathrm{NO}_{3}$ (Figure 7), and 100ppm $\mathrm{NO}_{3}$ (Figure 8). Four days later, GFP can only be found at 
100ppm $\mathrm{NO}_{3}$. The images show that E.coli $86-24-\mathrm{GFP}$ integrates more successfully, and with greater range on the slide, when the reactor is amended with $100 \mathrm{ppm} \mathrm{NO}_{3}$. This is an interesting observation, since both concentrations can be found in the natural environmental. If both of these conditions are considered oligotrophic, these results agree with current literature that lower nutrient conditions likely enhance foreign microbe persistence. However, the concentrations of nitrate used in this study suggest that E.coli 86-24-GFP will do better under slightly nutrient-enhanced environments. The concentration of $100 \mathrm{ppm} \mathrm{NO}$ was chosen specifically because it has been found at this level in groundwater throughout Canada (Environment Canada et al., 2001).
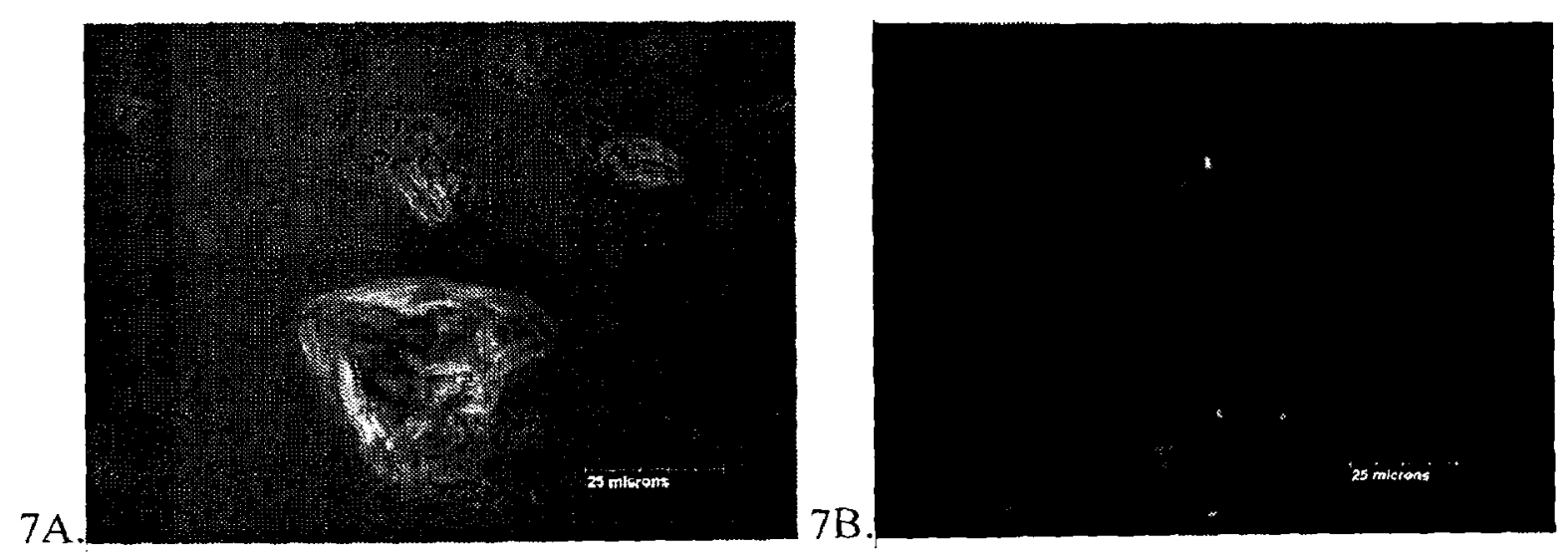

Figure 7: A. Reactor amended with $10 \mathrm{ppm} \mathrm{NO}_{3}, 5$ days after E.coli 86-24-GFP was added. B. Same image as 10A, under UV light. 

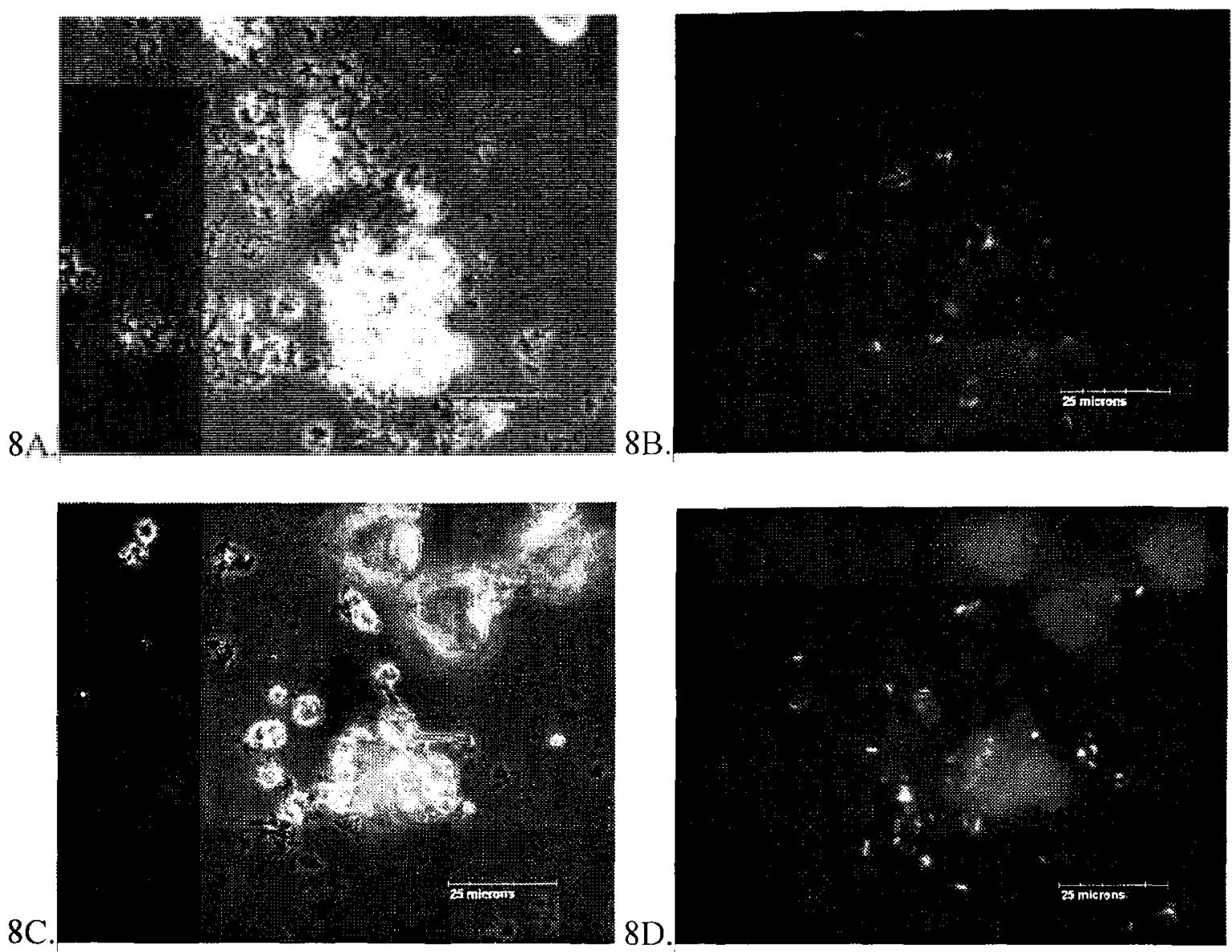

Figure 8: A (normal light) \& B (UV light), taken near the top of the slide, $100 \mathrm{ppm} \mathrm{NO}_{3}$, 5 days after E.coli 86-24-GFP was added. C (normal light) \& D (UV light), taken near the bottom of the slide, $100 \mathrm{ppm} \mathrm{NO}_{3}, 5$ days after E.coli $86-24-\mathrm{GFP}$ was added. 

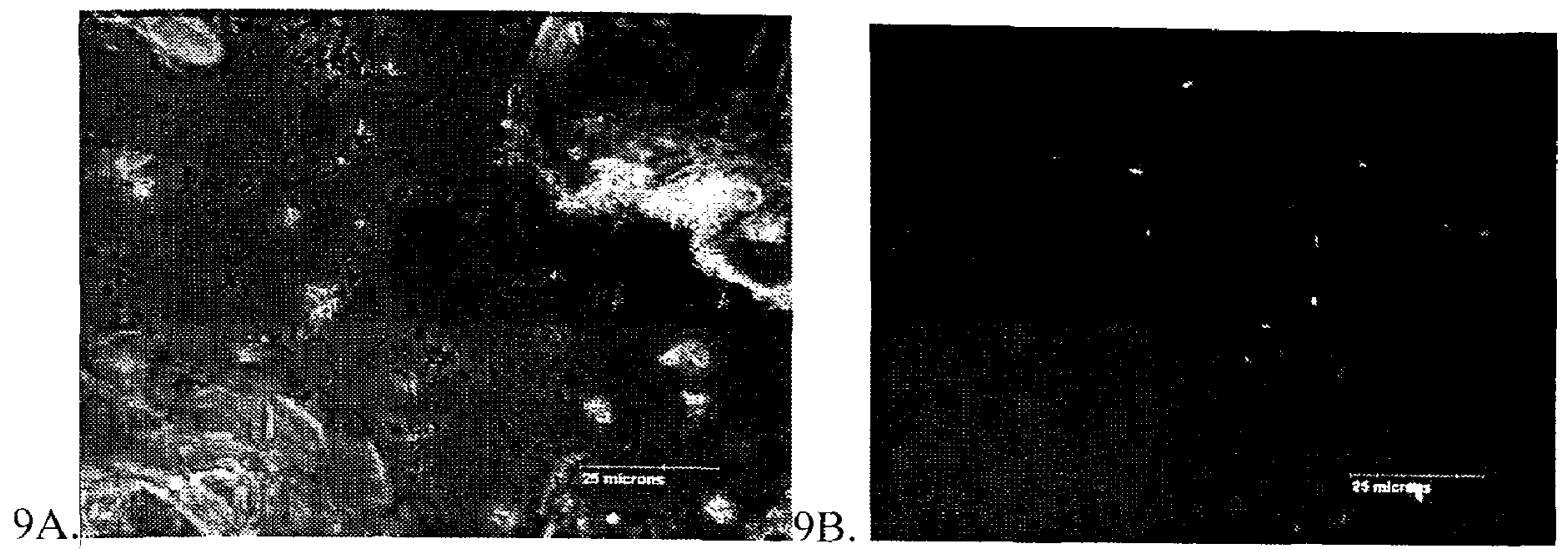

Figure 9: A (normal light) \& $\mathrm{B}$ (UV light), taken near the top of the slide, $100 \mathrm{ppm} \mathrm{NO}_{3}$, 9 days after E.coli 86-24-GFP added. GFP can no longer be captured for $10 \mathrm{ppm} \mathrm{NO}_{3}$ ammended reactor.

In experiments looking at phosphate effects, foreign microbe persistence was not enhanced, but the appearance of the biofilm was affected. Figure10A and 10B show E.coli $86-24-G F P$ clustering more closely than in experiments where no additional phosphate was added. The presence of phosphate seems to have a negative effect on persistence, since the GFP was detected over a longer period when phosphate was not added to the reactor. 

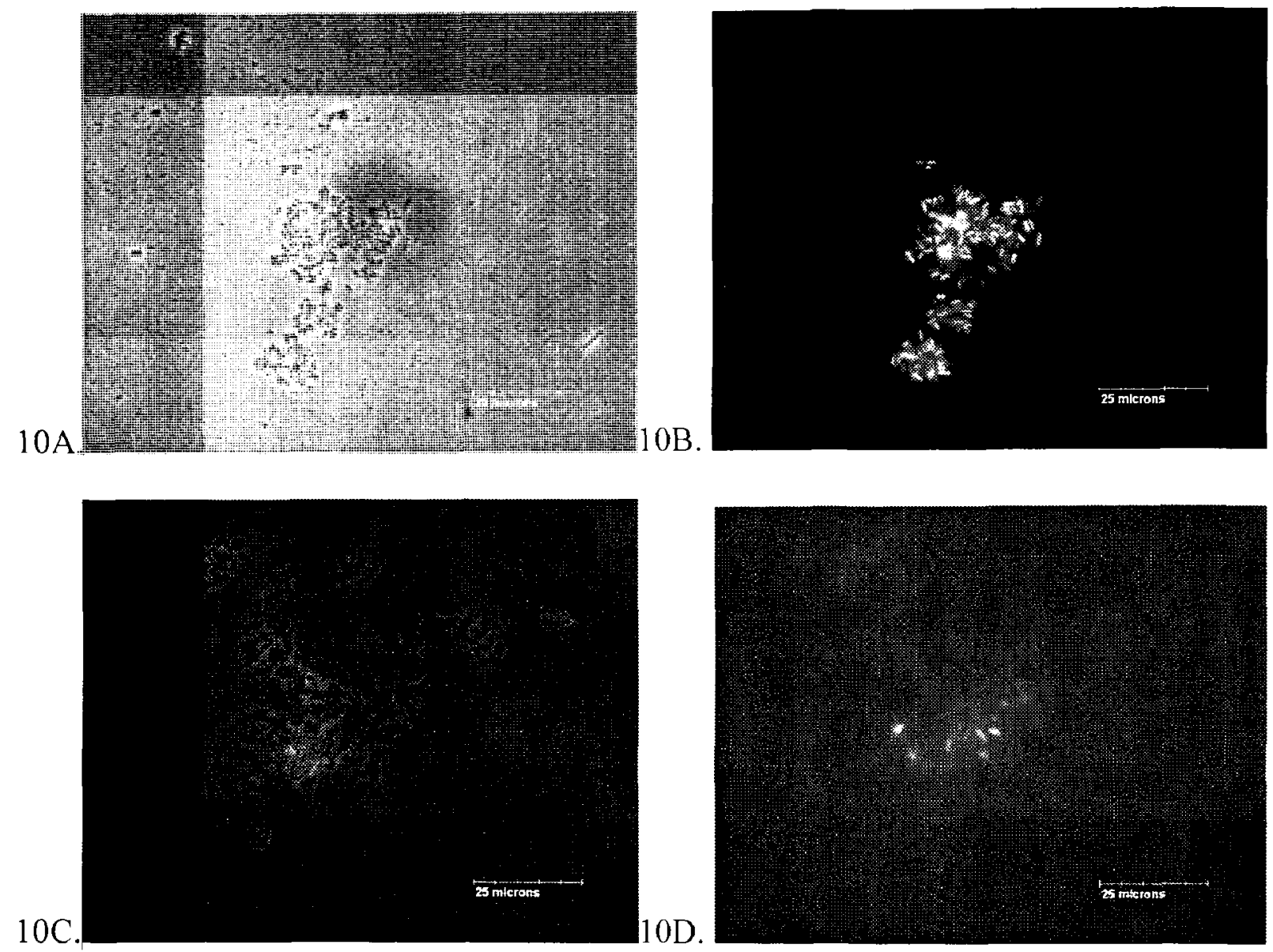

Figure 10: A (normal light) \& B (UV light). Taken 3 days after E.coli 86-24-GFP was

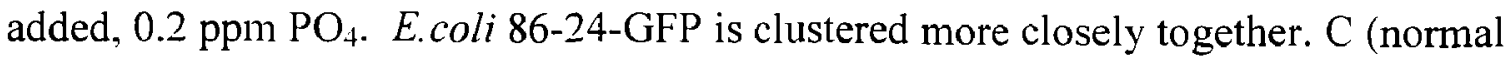
light), and D (UV light), taken 5 days after E.coli 86-24-GFP was added, 0.2 ppm $\mathrm{PO}_{4}$. The biofilm appears more developed, but the GFP is starting to fade. 
When adding phosphate and nitrate together, the foreign microbe initially appear to integrate very well with the biofilm on the slide, but even this combination experiences a quicker loss of GFP than a reactor amended with only $100 \mathrm{ppm} \mathrm{NO}$. A similar result is seen when phosphate and less nitrate are used (Figure 12).
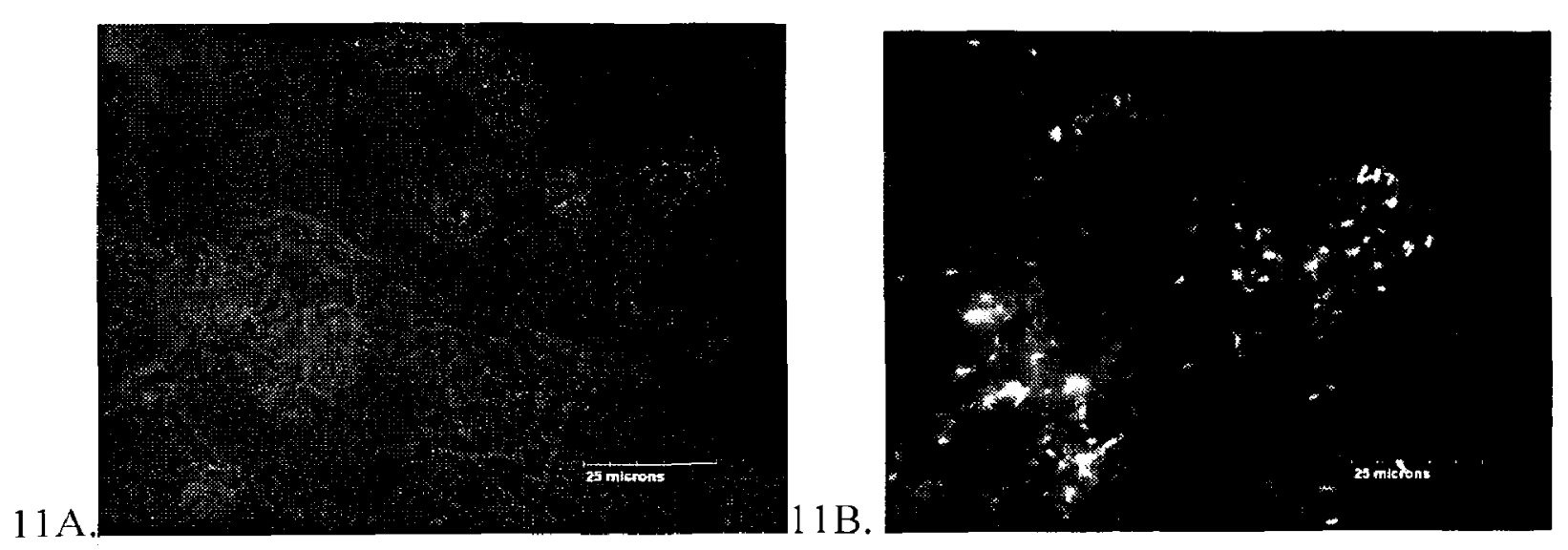

Figure 11: A (normal light) and B (UV light). Taken 5 days after E.coli was added, 0.2 ppm $\mathrm{PO}_{4}$ and $100 \mathrm{ppm} \mathrm{NO}$, 1000X. E.coli 86-24-GFP appears to be doing well, however, by day 11 , GFP can no longer be imaged. 

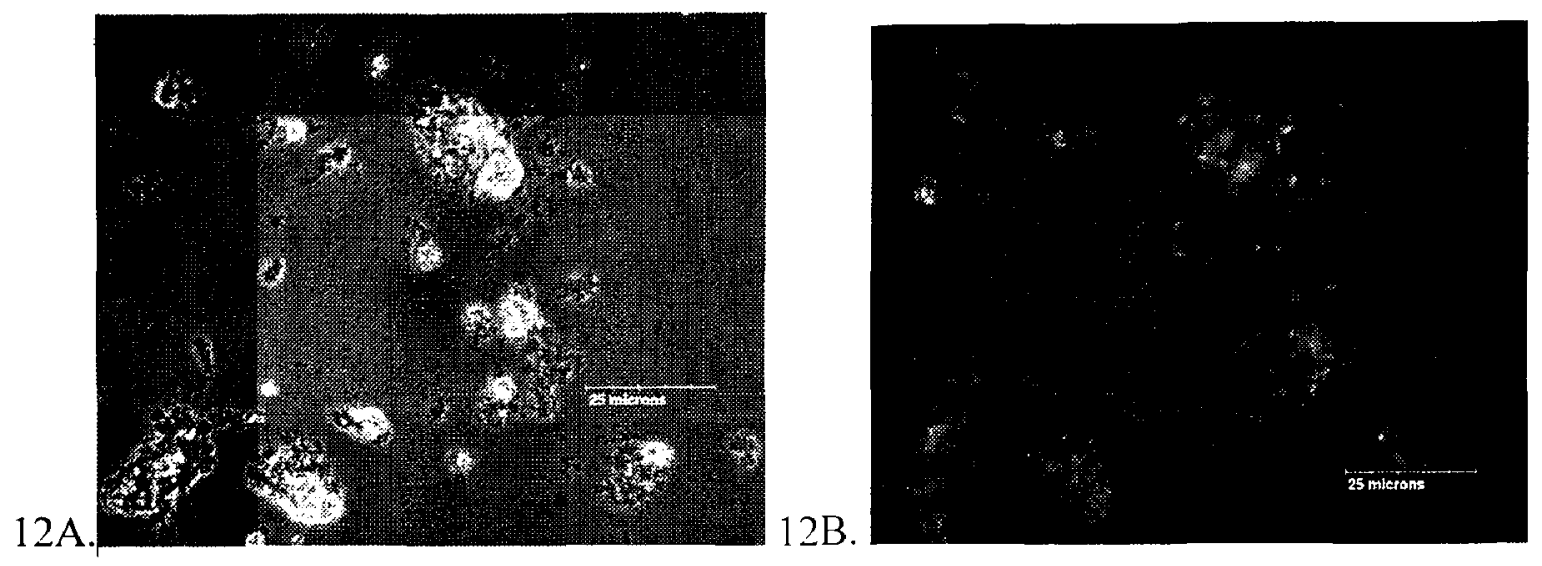

Figure 12: A (normal light) \& B (UV light), Taken 4 days after E.coli 86-24-GFP was added, amended with $0.2 \mathrm{ppm} \mathrm{PO}_{4}$ and $10 \mathrm{ppm} \mathrm{NO}_{3}$.

A unique observation in the reactor amended with $0.2 \mathrm{ppm} \mathrm{PO}_{4}$ and $100 \mathrm{ppm}$ $\mathrm{NO}_{3}$, was the inability of E.coli to grow right at the top of the water/air interface. A different filamentous-like microbe was seen to colonize this premium space, and E.coli 86-24-GFP was only found below it (Figure 13). 

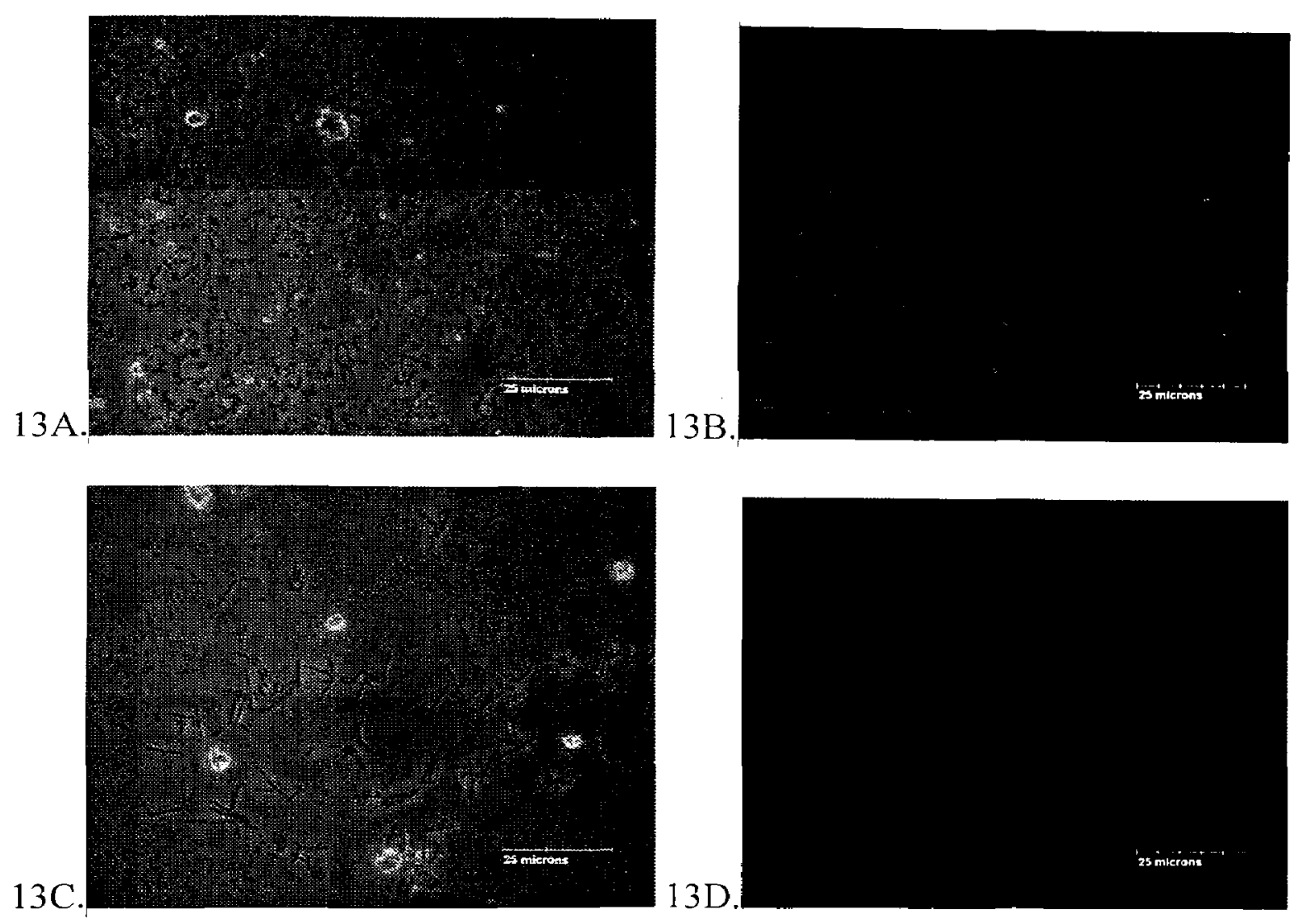

Figure 13: A (normal light), \& B (UV light), taken 4 days after E.coli 86-24-GFP was added, amended with $0.2 \mathrm{ppm} \mathrm{PO}_{4}$ and $100 \mathrm{ppm} \mathrm{NO}_{3}$. E.coli 86-24-GFP is doing well, but is not able to adhere to the biofilm or slide near the very top. There is good biofilm growth at the very top (16C), but no E.coli 86-24-GFP was found there (16D- UV light).

To add enhance the qualitative results, a quantitative result was also obtained. As previously described, one slide from each reactor was examined every time the reactor was sampled. Images were taken in an attempt to reflect the overall GFP fluorescence 
found on the slide. Persistence was measured using the GFP marker to count the total number of $E$. coli $86-24-G F P$ cells as they fluoresced in the biofilm. The goal was to provide further evidence that certain amended reactors created conditions where the E.coli 86-24-GFP was able to fluoresce for a longer period of time, reflecting a stronger ability to persist. The number of E.coli $86-24-G F P$ cells counted in all images taken during a single sampling from one reactor was then averaged.

When GFP was fading, the images represented nearly all E.coli 86-24-GFP still producing GFP. In the earlier samplings from the experiments, GFP was expressed over vast areas on the slide, so only representative images were taken. Slides with a lot of GFP, also had a greater range of growth. The numbers were averaged for each day, regardless of where on the slide they were taken. The averages are given for the area of the microscopic field of view, which was $12 \mathrm{~mm}^{2}$. With a slide that had too many E.coli 86-24-GFP to count, it was estimated to have at least 1000 cells in the image. The averaged numbers provide a numerical value for the persistence of E.coli $86-24-\mathrm{GFP}$ in the biofilm under the different nutrient conditions. The tally might underestimate the E.coli 86-24-GFP on the slides in the initial few days, but becomes more accurate later in the trial when the E.coli $86-24-G F P$ numbers start to decline. The results of the tally are shown in Figures 14-17. 


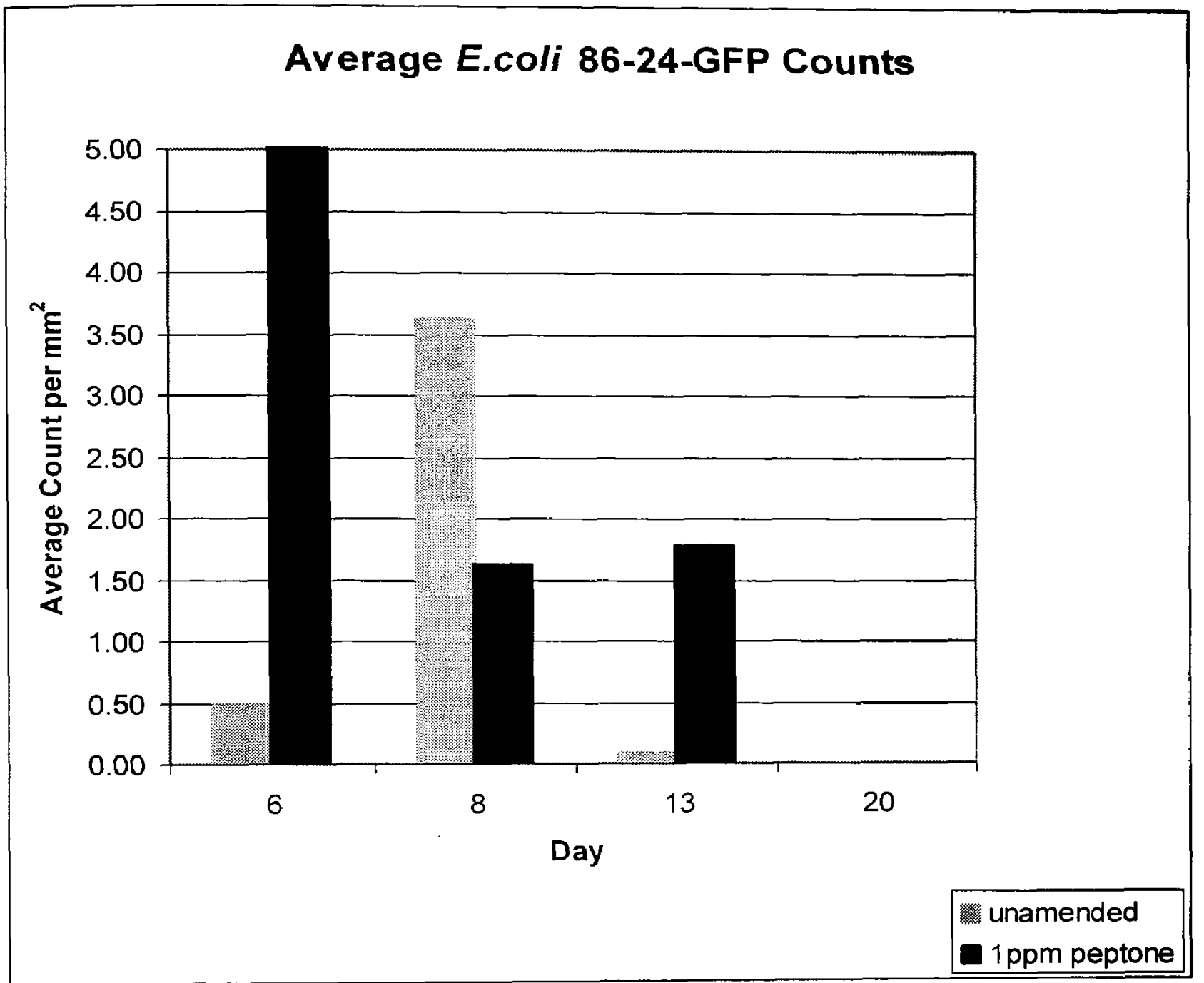

Figure 14. Trial One: Graphical representation of the averaged tallies obtained in an unamended reactor, and a reactor amended with $1 \mathrm{ppm}$ peptone. 


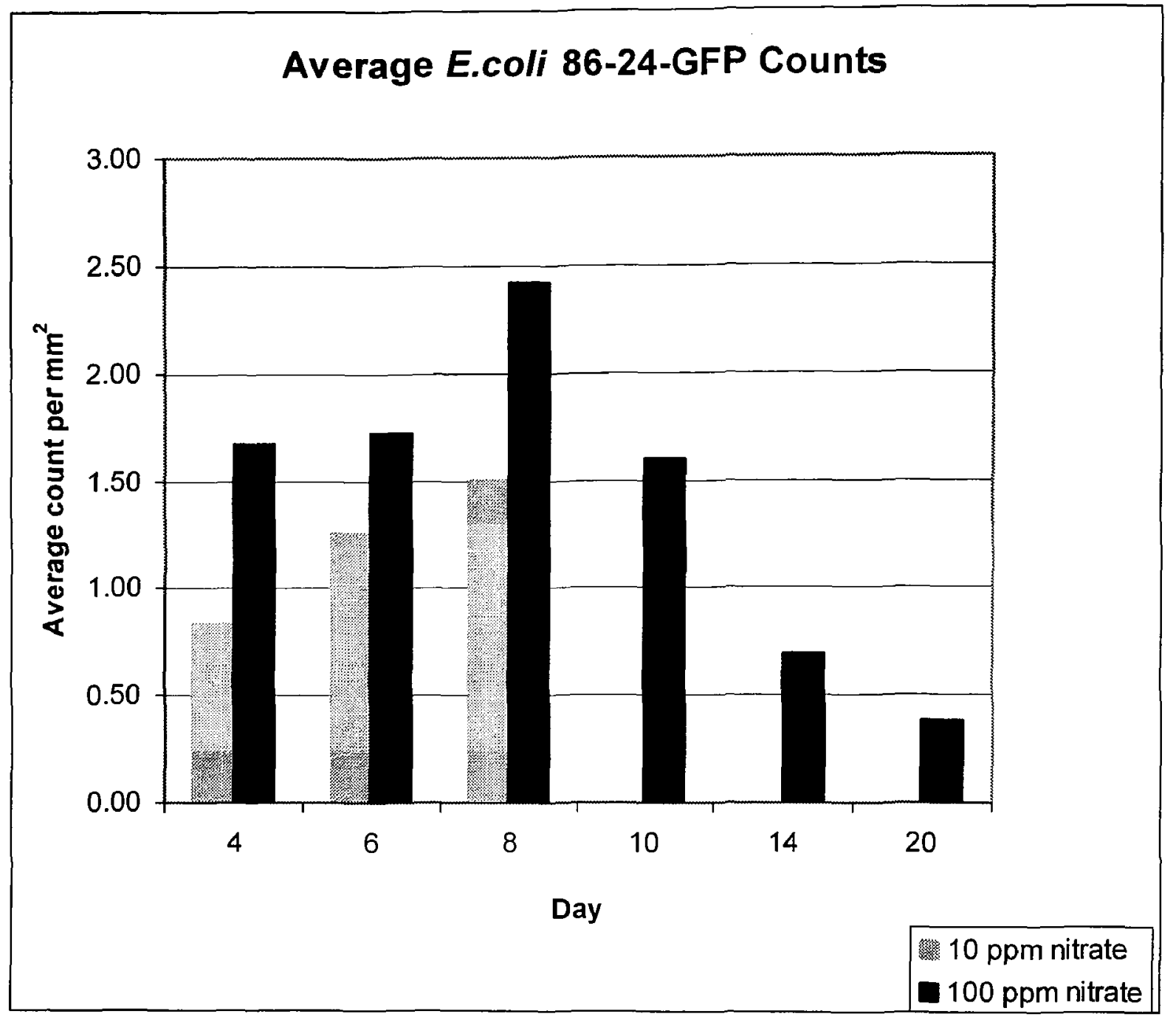

Figure 15. Trial Two: Graphical representation of the averaged tallies obtained from reactor conditions using $10 \mathrm{ppm}$ of nitrate, and $100 \mathrm{ppm}$ nitrate. 


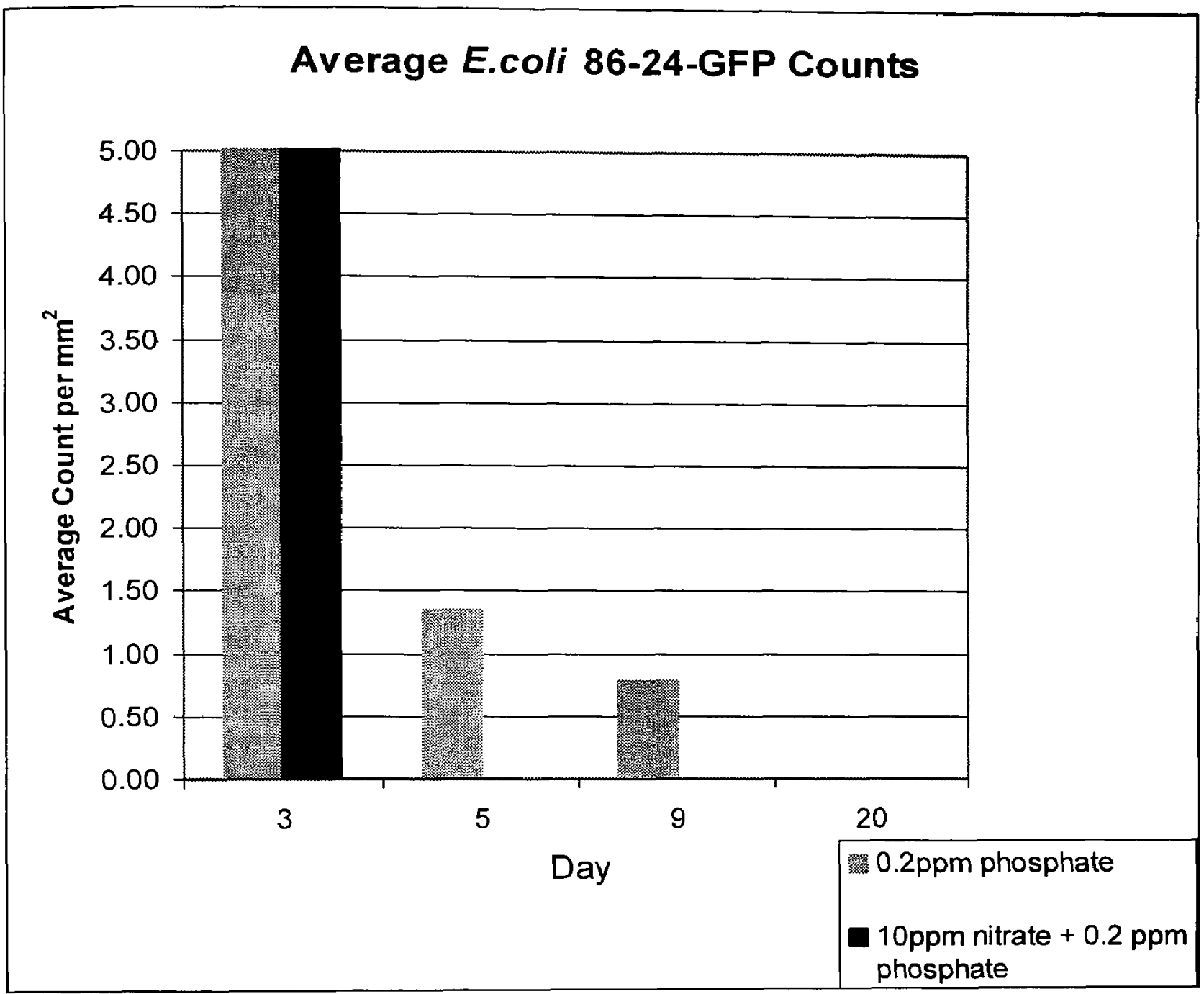

Figure 16. Trial Three: Graphical representation of the averaged tallies obtained from reactor conditions using $0.2 \mathrm{ppm}$ phosphate, and $10 \mathrm{ppm}$ nitrate with $0.2 \mathrm{ppm}$ phosphate. 


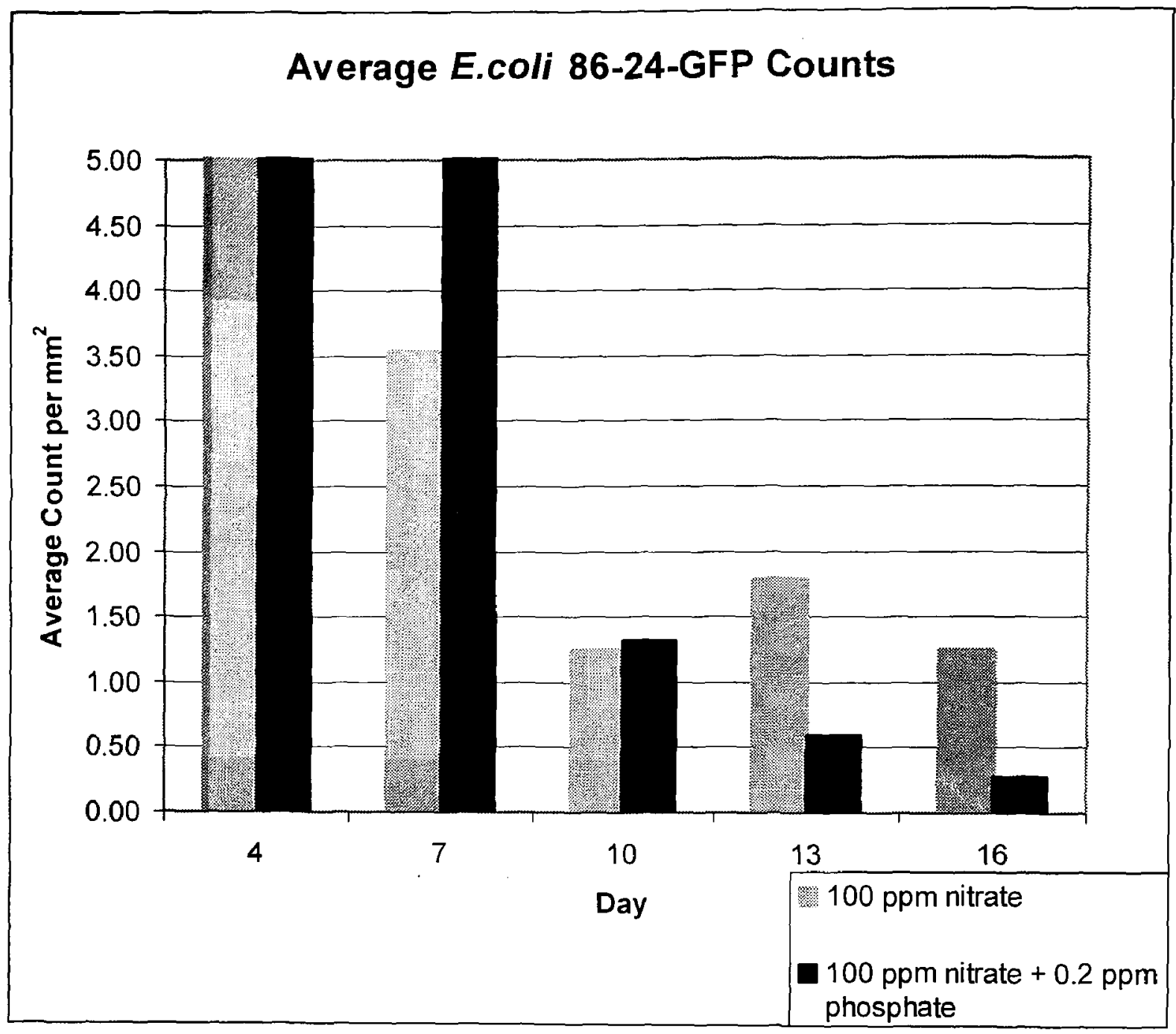

Figure 17. Graphical representation of the averaged tallies obtained from reactor conditions using $100 \mathrm{ppm}$ of nitrate, and $100 \mathrm{ppm}$ nitrate with $0.2 \mathrm{ppm}$ phosphate. 
A comparison of the graphs show that the average E.coli 86-24-GFP count increases to a maximum at 7-8 days after its initial introduction for the unamended reactor, and all reactors amended only with nitrate. After this time, the numbers decrease. The longest duration is found using $100 \mathrm{ppm}$ nitrate, where an average count of 0.38 cells $/ \mathrm{mm}^{2}$ is found at Day 20 (Figure 15). This is twice the amount of days that E.coli $86-24-G F P$ persisted when amended with only $10 \mathrm{ppm}$ nitrate (10 days). The second experiment that used $100 \mathrm{ppm}$ nitrate, ended at 16 Days (due to the limitation of 10 sampling slides), but the average count for that sampling day was 1.25 cells $/ \mathrm{mm}^{2}$. During this trial, the second reactor was also amended with phosphate. Despite also having $100 \mathrm{ppm}$ nitrate, the presence of phosphate appeared to cause a more rapid decline in E.coli $86-24-G F P$ cells. The average count at Day 16 for this experiment was 0.27 cells $/ \mathrm{mm}^{2}$ (Figure 17). The graphs provide evidence that E.coli 86-24-GFP counts remained higher over a longer duration. when the reactor was amended with $100 \mathrm{ppm}$ $\mathrm{NO}_{3}$. The reactors amended with phosphate, regardless of the presence or absence of nitrate, all showed an initially large amount of E.coli $86-24-G F P$ adherence followed by a rapid decline. The maximum average count at one week was also not observed. The lack of this growth peak was also absent when 1 ppm of peptone was used.

It was interesting to observe that although far more E.coli 86-24-GFP attached itself to the peptone-amended biofilm, this did not seem to significantly increase the length of time GFP was detected. The conditions with the least survivability were with $10 \mathrm{ppm} \mathrm{NO}_{3}$ amendments ( 8 days), and with the addition of $0.2 \mathrm{ppm} \mathrm{PO}_{4}$ (9 days), and the two combined ( 9 days). The exact day that GFP could be detected is not truly represented because sampling was not performed on a daily basis until an endpoint was 
reached, but the general findings still hold true. The presence of phosphate had an interesting visual effect appear on how E.coli 86-24-GFP clustered on the slide. It formed tighter groups than in the trials where no phosphate was added. Certain conditions also allowed E.coli $86-24-$ GFP to show variability for where it could be maintained on the slide (Figure 13). With $100 \mathrm{ppm} \mathrm{NO}_{3}$, the naturally-occurring biofilms occupied what was considered the premium location, the strip at the water-air interface. E.coli 86-24-GFP was observed to colonize below this area. In cases where the nutrient amendments were low, E.coli 86-24-GFP could be found in the water-air interface. 


\section{Use of molecular techniques}

The ability to detect $E$. coli $\mathrm{O} 157: \mathrm{H} 7$ in drinking water can help assure that a particular water supply is safe for consumption. Since the nature of this study was to obtain biofilms containing E.coli O157:H7, an opportunity was also provided to monitor the detection of E.coli 0157:H7 using molecular techniques. E.coli O157:H7 does not naturally produce GFP, so in this study one could compare persistence using the GFP marker, and detection based on DNA extraction and amplification. The results obtained using GFP were covered extensively in the previous section. This section details the results obtained using polymerase chain reaction (PCR), followed by analysis using denaturing high performance liquid chromatography (DHPLC). Previously designed PCR primers were selected to amplify part of a gene specific to E.coli O157:H7. DNA was obtained by scraping the biofilm from a reactor slide, and extracting it using commercially available kits. The PCR product obtained was then analyzed using DHPLC. The following figure is a sample of a chromatogram obtained. It includes six traces from Transgenomic's WAVE system, obtained under non-denaturing conditions. The bottom trace is Transgenomic's size ladder. The top three traces show a DNA peak just after 6 minutes, indicating a PCR product of approximately $500 \mathrm{bp}$. This indicates that the samples are positive for E.coli $86-24-\mathrm{GFP}$. The two other traces do not have a DNA peak, and therefore do not detect E.coli 86-24-GFP from the sample tested. 


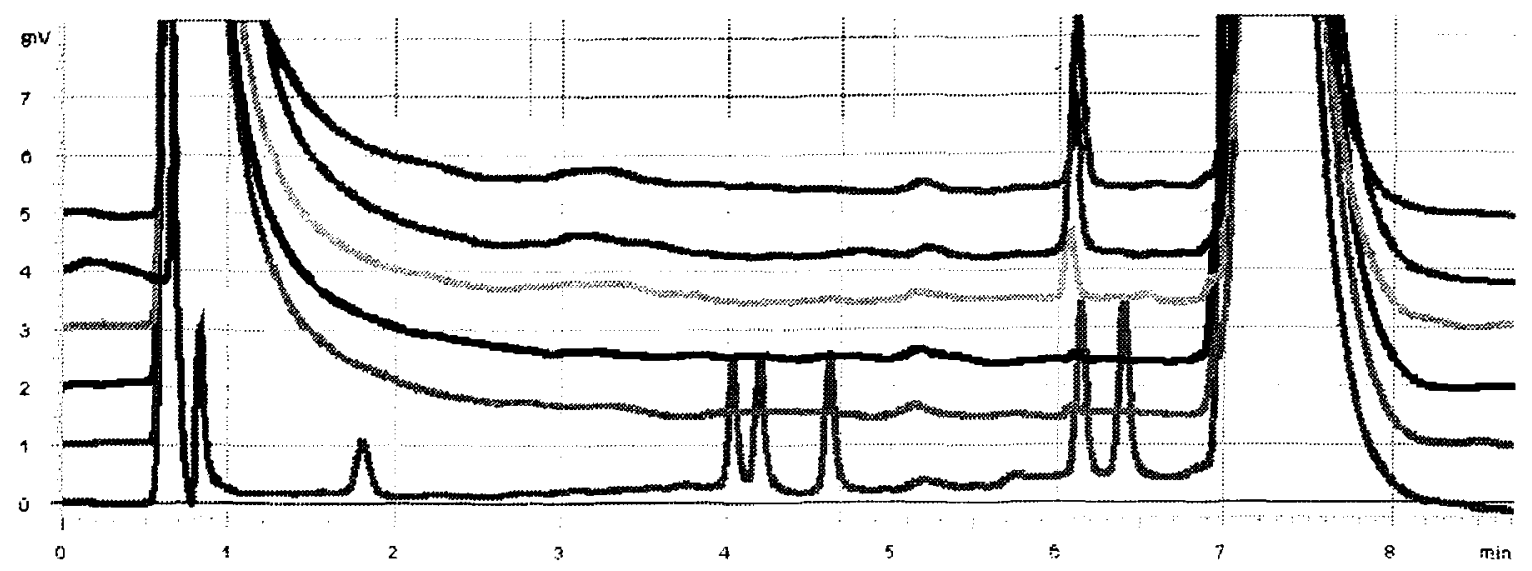

Figure 18: DHPLC Chromatogram obtained using O157-specific primers. The bottom trace is a size ladder available from Transgenomic, Inc. 
A comparison of the results obtained using microscopy and molecular-based techniques are summarized in the following table.

Table 8: Summary and comparison using O157 primers and GFP to monitor E.coli O157:H7 T86-24.

\begin{tabular}{|c|c|c|c|c|c|c|c|}
\hline Conditions & Experiment & Day 2 & Day 4 & Day 6 & Day 8 & Day 13 & Day 16 \\
\hline \multirow[t]{2}{*}{ unamended } & Microscope & $\begin{array}{c}\text { no } \\
\text { data }\end{array}$ & $\begin{array}{c}\text { no } \\
\text { data }\end{array}$ & ++ & ++ & + & -ve \\
\hline & O157 primers & ++ & ++ & -ve & $\begin{array}{l}\text { no } \\
\text { data }\end{array}$ & $-v e$ & -ve \\
\hline \multirow[t]{2}{*}{$\begin{array}{l}1 \mathrm{ppm} \\
\text { peptone }\end{array}$} & Microscope & $\begin{array}{l}\text { no } \\
\text { data }\end{array}$ & $\begin{array}{l}\text { no } \\
\text { data }\end{array}$ & +++ & ++ & t+ & + \\
\hline & O157 primers & + & ++ & ++ & $\begin{array}{c}\text { no } \\
\text { data }\end{array}$ & -ve & ++ \\
\hline \multirow[t]{2}{*}{$\begin{array}{l}10 \mathrm{ppm} \\
\text { nitrate }\end{array}$} & Microscope & + & + & + & + & -ve & -ve \\
\hline & O157 primers & -ve & -ve & -ve & -ve & -ve & -ve \\
\hline \multirow{2}{*}{$\begin{array}{l}100 \mathrm{ppm} \\
\text { nitrate }\end{array}$} & Microscope & +++ & +++ & +++ & +++ & +++ & + \\
\hline & O157 primers & ++ & ++ & ++ & + & + & -ve \\
\hline \multirow{2}{*}{$\begin{array}{l}0.2 \text { ppm } \\
\text { phosphate }\end{array}$} & Microscope & +++ & +++ & + & -ve & \multicolumn{2}{|c|}{ completed } \\
\hline & O157 primers & $\begin{array}{c}\text { no } \\
\text { data }\end{array}$ & + & -ve & -ve & \multicolumn{2}{|c|}{ completed } \\
\hline \multirow{2}{*}{$\begin{array}{l}0.2 \mathrm{ppm} \\
\mathrm{PO}_{4}, 10 \\
\text { ppm } \mathrm{NO}_{3}\end{array}$} & Microscope & ++++ & ++++ & + & -ve & \multicolumn{2}{|c|}{ completed } \\
\hline & O157 primers & $\begin{array}{c}\text { no } \\
\text { data }\end{array}$ & + & ++ & -ve & \multicolumn{2}{|c|}{ completed } \\
\hline \multirow[t]{2}{*}{$\begin{array}{l}100 \mathrm{ppm} \\
\text { nitrate }\end{array}$} & Microscope & ++++ & ++++ & +++ & +++ & + & completed \\
\hline & O157 primers & -ve & $\begin{array}{c}\text { no } \\
\text { data }\end{array}$ & -ve & -ve & -ve & completed \\
\hline \multirow{2}{*}{$\begin{array}{l}100 \text { ppm } \\
\mathrm{NO}_{3}, 0.2 \\
\text { ppm } \mathrm{PO}_{4}\end{array}$} & Microscope & ++++ & ++++ & +++ & + & + & completed \\
\hline & O157 primers & ++ & $\begin{array}{c}\text { no } \\
\text { data }\end{array}$ & $\begin{array}{c}\text { no } \\
\text { data }\end{array}$ & ++ & - ve & completed \\
\hline
\end{tabular}

Note: Microscope result, ++++ (very good GFP), +++ (good GFP), + (fair GFP), -ve(no GFP), PCR result, ++ (strong positive peak), + (weak positive peak), -ve (no peak). 
The results obtained using 0157-specific primers gave mixed results. In most cases, they failed to detect the presence of E.coli 86-24-GFP for the entire duration that GFP could be observed. Fifty percent of the time, E.coli 86-24-GFP could be detected 25 days longer by GFP than by PCR. Twenty-five percent of the PCR results were negative even when there was a strong amount of GFP seen using microscopy. The remaining twenty-five percent found the PCR to match the GFP results exactly. This lack of consistency was not a completely surprising finding, since PCR is inherently more complicated using genomic DNA extracted from an environmental sample. Inhibitory compounds, such as humic acids and heavy metals, can decrease polymerase activity (Rochelle, 2001). The PCR results do, however, demonstrate that using GFP as a tracer does work well. An actual endpoint cannot be established because it is unclear whether or not the E.coli 86-24-GFP died, or if its metabolic processes had slowed to the point where GFP was no longer produced.

To further investigate the biofilm using molecular techniques, 16S rRNA primers were also used. The different species of microbes present will amplify unique PCR products, reflected in base variation and product size. The same DNA samples were used as the template to amplify DNA from this conserved, but varied region of the genome. Collection and sequencing of the products obtained were considered beyond the scope of this project. The results were intended to obtain information on the amount of microbial diversity present, and to see if any conditions had an effect on the diversity of the 
microbial population. Analysis of 16S rRNA DNA products are often analyzed using DGGE, but in this study DHPLC was used due to its accessibility.

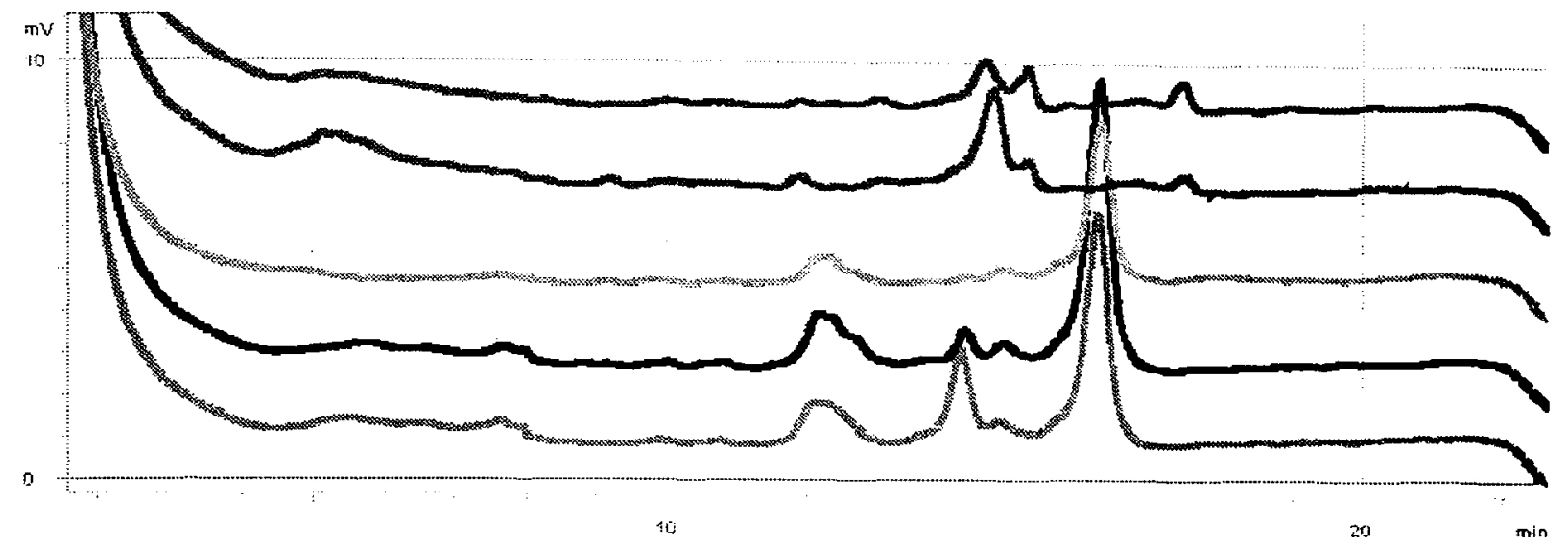

Figure 19: Selected chromatogram using 16S rRNA primers.

Figure 19 shows five traces from Transgenomic's WAVE, obtained under partially-denaturing conditions. The first two traces are from the same trial ( $1 \mathrm{ppm}$ peptone). The first and second trace reflects the sample obtained on Day 14 and Day 16, respectively. The third, fourth, and final trace, are from the same trial $\left(100 \mathrm{ppm} \mathrm{NO} \mathrm{N}_{3}\right)$, obtained from Day 3, Day 5, and Day 7, respectively. The peaks reflect DNA sequence variation within the PCR product due to the amplification of DNA from different microbes in the sample. Examination of the chromatograms suggests that the biofilm population changes over time. Since a large addition of E.coli 86-24-GFP was added to the reactor at the start of each experiment, it is likely that the largest peak seen at 16 minutes, on the final three traces, is from the E.coli. This peak would not be expected on the earlier two traces, because two weeks after the experiment, the GFP marker is no longer clearly seen when viewed using a microscope. 


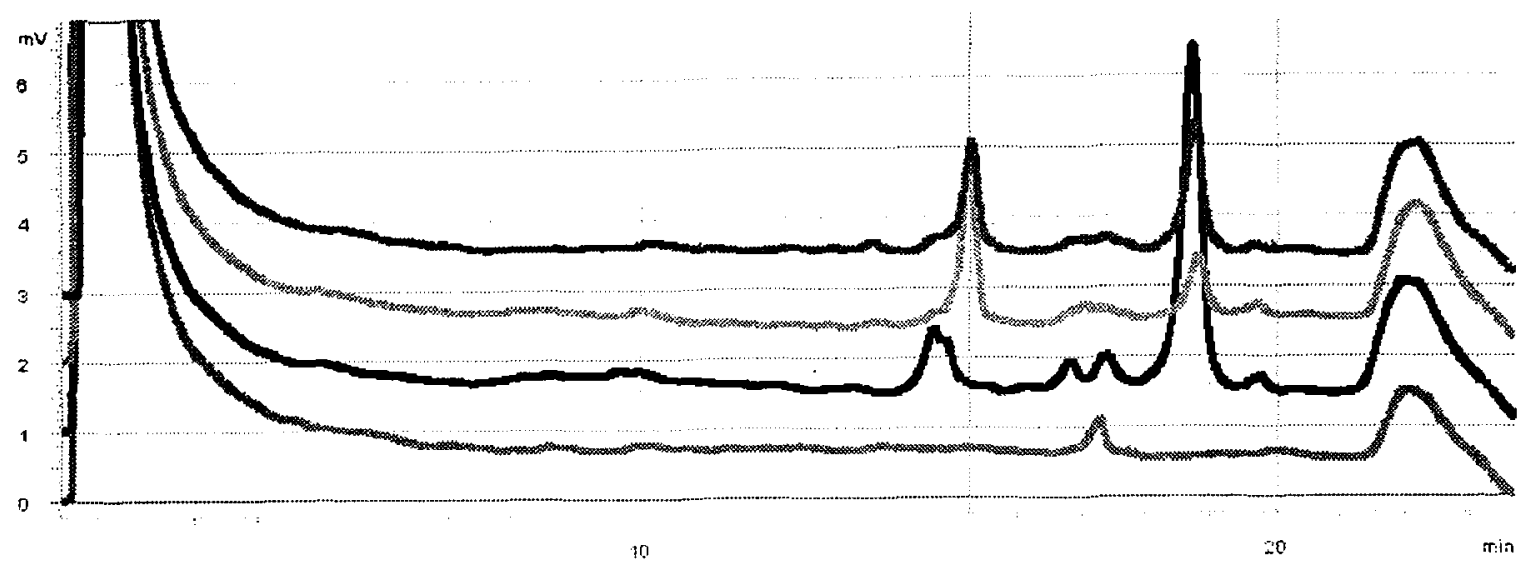

Figure 20: Selected chromatogram for 16S rRNA primers.

In Figure 20, the first two traces are from the same trial $\left(0.2 \mathrm{ppm} \mathrm{PO}_{4}\right.$ and $100 \mathrm{ppm}$ $\mathrm{NO}_{3}$ ). The first and second trace reflects the sample obtained on Day 4 and Day 10 , respectively.

The third trace is from a trial using $100 \mathrm{ppm} \mathrm{NO}_{3}$, and the final trace is a negative control. The phosphate amended results show two dominant peaks, whereas the trial with only nitrate added shows greater variation. This may indicate that there is greater species diversity when phosphate is not added to the reactor.

The combination of 16S rRNA primers and DHPLC shows good potential as means of monitoring species diversity for laboratory-scale annular reactors. However, there are inherent limitations when using 16S rRNA primers. Differential amplification can also distort the original template ratio and therefore not accurately representing the microbial population. Also, a single microorganism can contain multiple copies of the 
rRNA gene that can have slightly varied sequences. This would cause a false illusion of diversity in an environmental sample (Rochelle, 2001).

\section{Discussion}

The overall experimental design proved to work reliably throughout the fourmonth study. The motor used to create rotation of the slides did not fail, nor did any other component of the reactor fail. A couple of slides did slip from the clip holding it in place, and this was remedied by wrapping parafilm around the top edge of the slide that made contact with the clip. The tubing began to develop some mineral build-up, but at no time was the flow compromised. There was some concern about the consistency of the flow rate. The slower flow rate was compromised to achieve a consistent flow rate due to limitations of the pump that was used in the study. A pump capable of very slow flow rates should have been used, and would have allowed a constant flow, rather than alternating the flow off and on to conserve water. A further improvement on the reactor design would be to provide aeration of the water, which would then allow better biofilm growth over the entire surface of the slide. The challenge of counting GFP cells would have been more tedious, but the counts would also be more uniform throughout the slide. This unintended oxygen gradient, however, might be acceptable if the investigator does not want to create an oxygen-rich reactor which may not resemble the groundwater environment of some well-water biofilms. This would be true for lab-studies interested 
in understanding biofilms from deeper aquifers where oxygen would be less available. With respect to temperature, the bulk fluid was stored at $4^{\circ} \mathrm{C}$, and the reactors were kept at room temperature. Odgen et al., 2001, both found E.coli counts to be higher when the temperature was lower. The lack of temperature control, and performing the experiments at a room temperature, could have negatively effected E.coli survival. Finally, light exposure for the reactors was minimized to prevent algae growth. This was done by covering the reactors with cardboard boxes. No algae growth was seen on the walls of the reactor, or in the bulk fluid.

It was demonstrated that biofilms develop as a response to nutrient limitations. In these conditions, the biofilm was only a few micrometers thick. When $1 \mathrm{ppm}$ peptone was used in the bulk fluid, a thicker biofilm was observed. This might have then created a vertical gradient which then covered the E.coli $86-24-G F P$ that was introduced, thereby hindering its ability to persist. The less nutrient-rich conditions used, may have produced horizontal gradients, allowing the E.coli $86-24-G F P$ to have a better chance at survival.

The time given for biofilm development might not have been adequate. Since groundwater microbes can have very slow growth rates, a biofilm a few days old cannot be expected to truly represent the established biofilm that a foreign microbe would encounter. However, the reactor did find that E.coli 86-24-GFP does exist in a biofilm in nutrient poor conditions, as previously stated by Davey and O'Toole, 2000. Also, as with Banning et al., 2003, E.coli 86-24-GFP was found to colonize all layers of the biofilm and that groundwater biofilms do act as a reservoir.

A highly evolved microbe is able to fulfill its energy requirements using the smallest amount of energy expended (Baron, 1996). It was not clear if this strain of 
E.coli O157:H7 (86-24-GFP) was not able to compete with the other microbes present, or if it did become quiescent. The amendments used were done in an attempt to find differences in E.coli 86-24-GFP persistence, however, this might have also inadvertently created a competitive advantage for some of the naturally-existing microbes. 


\section{Conclusions}

It is possible to construct home-made annular reactors that can successfully develop biofilms using well water as the bulk fluid. The reactors can tolerate up to $1 \mathrm{ppm}$ of peptone without concern for planktonic growth. The reactors can also be successfully used as a laboratory model in studying nutrient effects on biofilms at environmentally-relevant concentrations.

A GFP-traceable foreign microbe can be successfully introduced and establish itself for days to weeks within the biofilm. GFP can be used as a viability marker in nutrient-limited conditions. It was therefore also demonstrated that the persistence of a foreign microbe in nutrient-limited conditions is dependent on its ability to integrate within an existing biofilm.

Nutrients, particularly nitrate, were used to amend the well-water in concentrations that have been detected in environmental samples. At $100 \mathrm{ppm} \mathrm{NO}_{3}$, E.coli 86-24-GFP showed the longest persistence. This was repeated twice during the study. Small amendments, and therefore, small increases in nutrients in the environment, could play a role in enhancing E.coli $86-24-G F P$ survivability. Extremely nutrient high water does not enhance E.coli $86-24-G F P$ survivability, likely due to an inability to compete with naturally-occurring microbes. The presence of other nutrients, phosphate in particular, can have an impact on the effects of nitrate on E.coli 86-24-GFP persistence. 
This study also found that $\mathrm{O} 157$-specific primers could successfully detect the presence of E.coli 86-24-GFP, but it was not consistent. This was unfortunate, since this lab study had the luxury of scraping the biofilm for direct analysis. This is unlike samples taken from a well, where it is only feasible to test the bulk fluid (the well water).

The use of DHPLC is limited by the ability to obtain good PCR product from $16 \mathrm{~S}$ rRNA primers. Analysis of the results obtained is limited because sequencing data was not obtained. As a result, this was only a preliminary study to look at the feasibility of using DHPLC in an environmental microbiology study. These initial findings do show potential. 


\section{Recommendations}

The experiments used in this study were largely exploratory. An attempt was made to use a variety of techniques that could be used together in studying well-water biofilms using a laboratory-based system. As such, a variety of recommendations can be made.

With respect to the home-made reactor, its design could be refined to produce a more uniform biofilm, as mentioned in the discussion. The coupons used in this study were all glass slides, but the use of stainless steel coupons should be revisited since some wells contain stainless steel well screens, and this is a common place for biofouling to occur. Camper et al., 1996, found that larger numbers of microbes grew on this substratum than on glass, but this study was not able to confirm that finding. Other substratum, such as various types of rocks typically found in contact with groundwater, could be explored.

With respect to biofilm development, it was only given a few days to develop. A series of experiments exploring biofilm age, by trying different development times and foreign microbe persistence, could be significant. As mentioned previously, the initial amount of E.coli 86-24-GFP added was probably far more than was necessary. Smaller amounts could be introduced to see if the same result would be obtained. Also, the growth rate of E.coli 86-24-GFP could have been further slowed, rather than simply relying on the cells to be in a stationary phase of growth. This ability of the cells to go from 24 hours in a nutrient-rich environment to the nutrient-poor reactor may not have allowed the cells to adequately adapt to these different conditions. A better transition 
could be attempted, and greater emphasis on this, as in Camper et al.'s 1996 study, was needed. In the case of nutrient effects. many permutations could be performed. There is a great possibility in exploring the potential effects of other pollutants, including heavy metals and pesticides, using the general system outlined in this study. Such experiments could test the finding of Artz and Killham, 2002, who found that E.coli O157 survival decreased with increasing copper and protozoa counts in field studies. As mentioned earlier, to test the GFP marker, it might have been useful to change the nutrient-poor reactors to more nutrient-rich conditions in an attempt to resuscitate the E.coli 86-24GFP. If GFP was seen after an attempt at resuscitation, it would indicate that the persistence of E.coli 86-24-GFP was even further enhanced by biofilm integration. If not, it would suggest that the biofilm only temporarily acts as a means of foreign microbe persistence.

The molecular techniques used in this study were not completely exhausted. The O157-specific primers were only moderately successful in detecting E.coli $86-24-G F P$ in the biofilm. Attempts to detect E.coli 86-24-GFP from both biofilm and water samples (e.g. reactor effluent), could be done. Collection by membrane filtration followed by PCR analysis could have been performed. The use the internal controls designed by Abdulmawjood et al., 2002, could also have been implemented.

The use of $16 \mathrm{~S}$ rRNA was not complete. Although great care was taken to choose well-tested primers, it was difficult to obtain any product. For the PCR that did produce DNA fragments, they could have been collected and sequenced for DNA comparison. Having sequence data that could be clustered, would also provide insight into the diversity of the species present. The experimental design provides the means of 
developing a biofilm of interest, to obtain its genomic DNA, and sequence PCR products to look for species that do not grow well using traditional culturing techniques. To further test the technologies used in this study, the use of DHPLC could have also been compared with DGGE to explore the pros and cons of each technique.

Lastly, a confocal laser scanning microscope was used throughout the study, yet the results obtained were not included in this final report. The goals set out in this study were achieved using an epifluorescence microscope. Since the biofilm was very thin, sectioned images of the biofilm was not necessary. However, the use of this tool could also create an even more in depth analysis of foreign microbe persistence, by looking at other characteristics of the biofilm. Staining techniques to compare the percent of the slide occupied by EPS, and other microbes with the GFP marker could further aid in the understanding of how a foreign microbe uses biofilm integration as a means of persistence. 


\section{References}

Abdulmawjood, A., Bulte, M., Coor, S., Roth, S., Schonenbrucher, H., and Hoorfar, J. 2003. Toward an international standard for PCR-based detection of Escherichia coli O157 Part 1. Assay development and multi-center validation. Journal of Microbiological Methods. 55: 775-786.

Abdulmawjood, A., Roth, S., and Bulte. M. 2002. Two methods for construction of internal amplification controls for the detection of Escherichia coli $\mathrm{O} 157$ by polymerase chain reaction. Molecular and Cellular Probes. 16:335-339.

Artz, R. and Killham, K. 2002. Survival of Escherichia coli O157:H7 in private drinking water wells: influences of protozoan grazing and elevated copper concentrations. FEMS Microbiology Letters 216: 117-122.

Baker, G., Smith, J., Cowan, D. 2003. Review and re-analysis of domain-specific 16S primers. Journal of Microbiological Methods. 55: 541-555.

Banfield, J. \& Nealson, K. 1997. Geomicrobiology: Interactions between Microbes and Minerals. Reviews in Mineralogy. Volume 35. The Mineral Society of America. Washington, D.C.

Banning, N., Toze, S., Mee, B. 2003. Persistence of biofilm-associated Escherichia coli and Pseudomonas aeruginosa in groundwater and treated effluent in a laboratory model system. Microbiology. 149: 47-55.

Baron, S. 1996. Medical Microbiology $4^{\text {th }}$ Edition. The University of Texas Medical Branch at Galveston.

Bennett, P., Hiebert, F., Rogers, J. 2000. Microbial control of mineral-groundwater equilibria: Macroscale to microscale. Hydrogeology Journal. 8: 47-62.

Biksey, T., and Gross, E. The hyporhetic zone: linking groundwater and surface waterunderstanding the paradigm. Remediation. 2001. 
Bilge, S., Vary, J., Dowell, S., Tarr, P. 1996. Role of the Escherichia coli O157:H7 O side chain in adherence and analysis of an $\mathrm{rfb}$ locus. Infection and Immunology. 64: 4795-4801.

Boon, N., Windt, W., Verstraete, W., Top, E. 2002. Evaluation of nested PCR-DGGE (denaturing gradient gel electrophoresis) with group-specific 16S rRNA primers for the analysis of bacterial communities from different wastewater treatment plants. 39: 101112.

Boon, N., Marie, C., Top, E., Verstraete. 2000. Comparison of the spatial homogeneity of physico-chemical parameters and bacterial $16 \mathrm{~S}$ rRNA in sediment samples from a dumping site for dredging sludge. Applied Microbiology and Biotechnology. 53: 742747.

Borch, M., Smith, S., Noble, L. Evaluation and restoration of water supply wells. AWWA Research Foundation and American Water Works Association. Denver, 1993

Brock, T., and Madigan, M. Biology of Microorganisms. Prentice Hall. New Jersey, 1991.

Butterfield, P., Camper, A., Ellis, B., Jones, W. 2002. Chlorination of model drinking water biofilm: implications for growth and organic carbon removal. Water Research. 36: 4391-4405.

Camper, A., Jones, W., Hayes, J. 1996. Effect of Growth Conditions and Substratum composition on the persistence of coliforms in mixed-population biofilms. Applied and Environmental Microbiology. 62(11): 4014-4018.

Cepuder, P., and Shukla, M. 2002. Groundwater nitrate in Austria: a case study in Tullnerfeld. Nutrient Cycling in Agroecosystems. 64: 301-315.

Clark, G., Price, L., Ahmed, R., Woodward, D., Melito, P., Rodgers, F., Jamieson, F., Ceibin, B., Li, A., Ellis, A., 2003. Characterization of waterborne outbreak-associated Campylobacter jejuni, Walkerton, Ontario. Emerging Infectious Diseases. 9(10): 12321241. 
Cooksey, R., Morlock, G., Holloway, B., Limor, J., Hepburn, M. 2002. Temperaturemediated heteroduplex analysis performed using denaturing high-performance liquid chromatography to identify sequence polymorphisms in Mycobacterium tuberculosis complex organisms. Journal of Clinical Microbiology. 40(5): 1610-1616.

Datry, T., Malard, F., Gibert, J. 2004. Dynamics of solutes and dissolved oxygen in shallow urban groundwater below a stormwater infiltration basin. Science of the Total Environment. 329: 215-229.

Davey, M., and O'Toole, G. 2000. Microbial Biofilms: from ecology to molecular genetics. Microbiology and Molecular Biology Reviews. 64(4): 847-867.

Dewettinck, T., Hulsbosch, W., Van Hege, K., Top, E., Verstraete, W. 2001. Molecular fingerprinting of bacterial population in groundwater and bottled mineral water. Applied Microbiology and Biotechnology. 57: 412-418.

Dodd, C., Sanderson, M., Sargeant. J., Nagaraja. T., Oberst. R., Smith, R., Griffin, D. 2003. Prevalence of Escherichia coli O157 in cattle feeds in Midwestern feedlots. Applied and Environmental Microbiology. Applied and Environmental Microbiology. 69(9): 5243-5247.

Domann, E., Hong, G. Imirzalioglu, C.. Turschner, S., Kuhle, J., Watzel, C., Hain, T., Hossain, H., Chakraborty, T. 2003. Culture-independent identification of pathogenic bacteria and polymicrobial infections in the genitourinary tract of renal transplant recipients. Journal of Clinical Microbiology. 41(12): 5500-5510.

Eaves, D., Liebana, E., Woodward, M., Piddock, L. 2002. Detection of gyrA mutations in auinolone-resistant Salmonella enterica by denaturing high-performance liquid chromatography. Journal of Clinical Microbiology. 40: 4121-4125.

Environment Canada, Indicators and Assessment Office. Ecosystem Science Directorate, Environmental Conversvation Service. 2001. Nutrients in the Canadian environment. National Library of Canada.

Gagliardi, J. and Karns, J. 2000. Leaching of Escherichia coli O157:H7 in diverse soils under various agricultural management practices. Applied and Environmental Microbiology. Applied and Environmental Microbiology . 66(3): 877-883. 
Griffin, A., West, S., Buckling, A. August 2004. Cooperation and competition in pathogenic bacteria. Nature 430: 1024-7.

Hall-Stoodley, L., Casterton, P. and Stoodley P. 'Bacterial Biofilms: From the Natural Environment to Infectious Diseases', Nature Reviews Microbiology, 2(2): 95-108, 2004.

Hannachi-M'Zali, F., Ambler, J., Taylor, C., Hawkey, P. 2002. Examination of single and multiple mutations involved in resistance to quinolones in Staphylococcus aureus by a combination of PCR and denaturing high-performance liquid chromatography (DHPLC). Journal of Antimicrobial Chemotherapy. 50: 649-55.

Hayashi, T., Makino, K., Ohnishi, M., Kurokawa, K, Ishii K., Yokoyama K., Han, C., Ohtsubo, E., Nakayama K., Murata, T., Tanaka M., Tobe, T., Iida, T., Takami, H., Honda, T., Sasakawa, C., Ogasawara, N., Yasunaga, T., Kuhara, S., Shiba, T., Hattori, M., Shinagawa, H. 2001. Complete genome sequence of enterohemorrhagic Escherichia coli O157:Hy and genomic comparison with a laboratory strain K12. DNA Research. $8(1): 11-22$.

Hoppert, M. Microscopic Techniques in Biotechnology. Wiley-VCH, Germany. 2003

Hurtle, W., Shoemaker, D., Henchal, E., Norwood, D. 2002. Denaturing HPLC for Identifying Bacteria. Biotechniques. 33: 386-391.

Ibekwe, A., Grieve, C., Lyon, R. 2003. Characterization of microbial communities and composition in constructed dairy wetland wastewaster effluent. Applied and Environmental Microbiology. Applied and Environmental Microbiology. 69(9): 50605069.

Islam, M., Siddika, A., Khan, M., Goldar, M., Sadique, M., Kabir, A., Huq, A., Colwell, R. 2001. Microbiological analysis of tube-well water in a rural area of Bangladesh Applied Environmental Microbiology. 67(7): 3328-3330.

Jain, D. 1995. Microbial colonization of the surface of stainless steel coupons in a deionized water system. Water Research. 29(8): 1869-1876. 
Kaper, J., Nataro, J., Mobley, H. 2004. Pathogenic Escherichia coli. Nature Reviews Microbiology. 2(2): 123-140.

Kemp, M., and Dodds, W. 2001. Spatial and temporal patterns of nitrogen concentrations in pristine and agriculturally-influenced prairie streams. Biogeochemistry. 53: $125-141$.

Kudva, I., Evans, P., Perna, N., Barrett. T.. Ausubel, F., Blattner, F., Calderwood, S. 2002. Strains of Escherichia coli O157:H7 differ primarily by insertions or deletions, not single-nucleotide polymorphisms. Journal of Bacteriology. 184(7): 1873-1879.

Law, D. 2000. The history and evolution of Escherichia coli 0157 and other Shiga toxin-producing E. coli. World Journal of Microbiology and Biotechnology. 16: 701709 .

Lawrence, J., Swerhone, G., Neu, T. A simple rotating annular reactor for replicated biofilm studies. Journal of Microbiological Methods. 42: 215-224.

Loehr, R. 1974. Agricultural waste management: problems, processes, and approaches. New York Academic Press, New York.

Maier, R., Pepper, I., and Gerba, C. Evironmental Microbiology. Academic Press, London, UK. 2000.

McKeon, D., Calabrese, J., Bissonnette, G. 1995. Antibiotic resistant gram-negative bacteria in rural groundwater supplies. Water Research. 29-8: 1902-1908.

Michell, R. Environmental Microbiology. Wiley-Liss. Cambridge. 1992

Nuzman C. Groundwater and Well Efficiency. Doerr Metal Products, Kansas. 1978.

Odgen, I., Fenlon, D., Vinten, A., Lewis, D. 2001. The fate of Escherichia coli O157 in soil and its potential to contaminate drinking water. International Journal of Food Microbiology 66: 111-117.

Ostrowski, M., Cavicchioli, R., Blaauw, M., Gottschal, J. 2001. Specific growth rate plays a critical role in hydrogen peroxide resistance of the marine oligotrophic 
ultramicrobacterium Sphingomonas alaskensis RB2256. Applied and Environmental Microbiology. 67(3): 1292-1299.

Ovreas, L., Forney, L., Daae, F., Torsvik, V. 1997. Distribution of bacterioplankton in meromictic lake saelenvannet, as determined by denaturing gradient gel electrophoresis of PCR-amplified gene fragments coding for 16S rRNA. Applied and Environmental Microbiology. 63-9: 3367-3373.

Porter J., Mobbs, K., Hart, C., Saunders, J., Pickup, R., Edwards, C. 1997. Detection, distribution, and probable fate of Escherichia coli O157 from asymptomatic cattle on a dairy farm. Journal of Applied Microbiology. 83: 297-306.

Peyton, B. 1996. Effects of shear stress and substrate loading rate on Pseudomonas aeruginosa biofilm thickness and density. Water Research. 30(1): 29-36.

Premstaller, A., Oefner, P. Feb.2003. Denaturing HPLC of Nucleic Acids. Pharmagenomics. p20-36.

Rice, A., Hamilton, M., Camper, A. 2000. Apparent surface associated lag time in growth of primary biofilm cells. Microbial Ecology. 41: 8-15.

Rice, A., Hamilton, M., Camper, A. 2003. Movement, replication, and emigration rates of individual bacteria in a biofilm. Microbial Ecology. 45: 163-172.

Rivas, R., Velazquez, E., Zurdo-Pineiro, J., Mateos, P., Molina, E. 2004. Identification of microorganisms by PCR amplification and sequencing of a universal amplified ribosomal region present in both prokaryotes and eukaryotes. Journal of Microbiological Methods. 56: 413-426.

Rochelle, P. 2001. Environmental Molecular Microbiology: Protocols and Applications. Horizon Press, Norfolk, England.

Safe Drinking Water Act, 2002. Ontario Regulation 169/03 Schedule 2. Drinking Water Quality Standards. 
Sauer, K., Camper, A., Ehrilich J., Costerto, J., Davies, D. 2002. Pseudomonas aeruginosa displays multiple phenotypes during development as a biofilm. Journal of Bacteriology 184:1140-54.

Savoline, J. The New Tanner: "Acton water safe chairman confirms". Thursday December 9, 2004.

Scheuerman, T., Camper, A., Hamilton, M. 1998. Effects of substratum topography on bacterial adhesion. Journal of Colloid and Interface Science. 208: 23-33.

Schwartz, F., and Zhang, H. 2003. Fundamentals of Groundwater. John Wiley and Sons. New York, USA.

Shirtliff, M., Mader, J., Camper, A. 2002. Molecular interactions in biofilms. Chemistry and Biology. 9: 859-871.

Shlush, L., Behar, D., Zelazny, A., Keller, N. Lupski, J., Beaudet, A., Bercovich, D. 2002. Molecular epidemiological analysis of the changing nature of a meningococcal outbreak following a vaccination campaign. Journal of Clinical Microbiology. 40(10): 3565-3571.

Skopek, T. R., Glaab, W. E., Monroe, J. J., Kort. K. L.. and Schaefer, W. 1999. Analysis of sequence alterations in a defined DNA region: Comparison of temperature modulated heteroduplex analysis and denaturing gradient gel electrophoresis. Mutat. Res. 430:13-21

So, J., Lim, H.T., Oh, E., Heo, T., Koh. S., Leung, K.T., Lee, H., Trevors, J.T. 2002. Visualizing the infection process of Xanthomonas campetris in cabbage using green fluorescent protein. World Journal of Microbiology and Biotechnology. 18: 17-21.

Soini, S., Koskinen, K., Vilenius, M., Puhakka, J. 2002. Effects of fluid-flow velocity and water quality on planktonic and sessile microbial growth in water hydraulic system. Water Research. 36: 3812-3820.

Stewart, P., Murga, R., Srinivasan, R., DeBeers, D. 1995. Biofilm structure heterogeneity visualized by 3 microscopic techniques. Water Research. 8: 2006-2009. 
Varnam, A., Evans, M. 2000. Environmental Microbiology. Manson Publishing Ltd, London UK.

Wang, L., and Reeves, P. 1998. Organization of Escherichia coli $\mathrm{O} 157 \mathrm{O}$ antigen gene cluster and identification of its specific genes. Infection and Immunity. 66(8): 35453551 .

Watanabe, K., Watanabe, K.. Kodama. Y., Syutsubo, K., Harayama, S. 2000. Molecular characterization of bacterial populations in petroleum-contaminated groundwater discharged from underground crude oil storage cavities. Applied and Environmental Microbiology. 66(11): 4803-4809.

Watanabe, K., Kodama. Y.. Harayama. S. 2001. Design and evaluation of PCR primers to amplify bacterial $16 \mathrm{~S}$ ribosomal DNA fragments used for community fingerprinting. Journal of Microbiological Methods. 44: 253-262.

Webb, D., Hamilton. M.. Harkin. G.. Lawrence. S.. Camper, A., Lewandowski, Z. 2003. Assessing technician effects when extracting quantities from microscope images. Journal of Microbiological Methods. 53: 97-106.

White, D., Palmer. R.. Zinn. M... Smnith C.. Burkhalter. R., Macnaughton S., Whitaker, K., Kirkegaard, R. 1999. Manilipuliation of thiofillm microbial ecology. Engineered

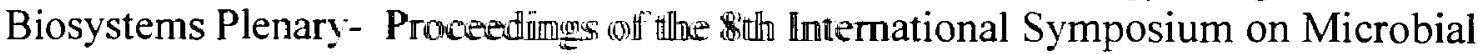
Ecology. Halifax.

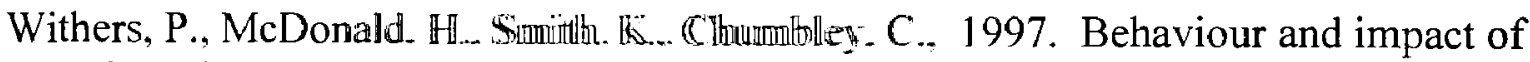

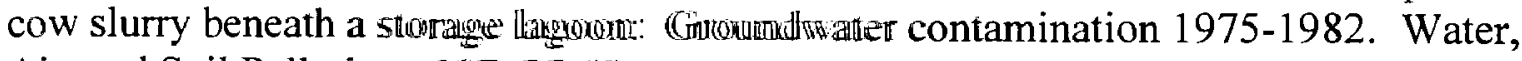
Air, and Soil Pollution. 10(077: 3.5-49).

Yokoigawa, K., Takikawa. A.. Kawwail. HH. 1969. Difference between Escherichia coli O157:H7 and non-pathogemic E. colp: Surrvivall and growth in seasonings. Journal of Bioscience and Bioengineering. 8 $8(5): 574-576$

Websource: Glen Armstrong: http//exn.ca/stories/2000/06/07/53.asp

Websource: www.ene.gov.on.ca/envision/techdocs/4000e $01 . h t m$

Websource: http://www.pscanalytical.com/tech/qualityguide.asp. 
Websource: www.nupge.ca/news_2003/n12au03b.htm

Websource: http://www.ene.gov.on.ca/envision/water/sdwa/status_part2.htm Websource: http://www.ene.gov.on.ca/envision/water/sdwa/status_part1.htm

Websource: http://www.imt.net/ mitbst/reactors.html 
B oc -74.147 